\title{
State of the art in simulation-based optimisation for maintenance systems
}

\author{
Abdullah Alrabghi and Ashutosh Tiwari \\ Manufacturing Department \\ Cranfield University \\ Cranfield, United Kingdom \\ a.alrabghi@cranfield.ac.uk, a.tiwari@cranfield.ac.uk
}

\begin{abstract}
Recently, more attention has been directed towards improving and optimising maintenance in manufacturing systems using simulation. This paper aims to report the state of the art in simulation-based optimisation of maintenance by systematically classifying the published literature and outlining main trends in modelling and optimising maintenance systems. The authors investigate application areas and published real case studies as well as researched maintenance strategies and policies. Much of the research in this area is focusing on Preventive Maintenance and optimising Preventive Maintenance frequency that will lead to the minimum cost. Discrete Event Simulation was the most reported technique to model maintenance systems whereas modern optimisation methods such as Genetic Algorithms was the most reported optimisation method in the literature. On this basis, the paper identifies the current gaps and discusses future prospects. Further research can be done to develop a framework that guides the experimenting process with different maintenance strategies and policies. More real case studies can be conducted on multi-objective optimisation and Condition Based Maintenance especially in a production context.
\end{abstract}

Keywords: simulation, optimisation, maintenance, modelling, review

CBM: Condition Based Maintenance

$\mathrm{CM}$ : Corrective Maintenance

DES: Discrete Event Simulation

GA: Genetic Algorithms

PM: Preventive Maintenance

SA: Simulated Annealing 


\section{Introduction}

Maintenance aims to combat the inevitable degradation of assets over their operational lifetime and keep them in a working order. Therefore, maintenance plays an important role in sustaining and improving assets availability, which in turn affects the productivity of the system in interest.

Recently, more attention has been directed towards improving and optimising maintenance in manufacturing systems. Maintenance cost can reach anywhere between $15 \%$ and $70 \%$ of production costs [1]. Wang [2] observes that there is still a large potential for increasing the productivity in current maintenance practices. In some industries, a slight improvement in throughput could result in significant economic impact [3]

Simulation delivers an advantage over analytical approaches because many maintenance policies are not analytically traceable [4]. In addition, it allows experimenting and better understanding of complex systems [5].

The complexity of maintenance systems has increased significantly $[4 ; 6]$. This is partly due to modern manufacturing systems which involve numerous interactions and dependencies between components. It is evident that analytical and mathematical approaches are limited in solving such complex maintenance problems. By developing both analytical and simulation models to solve the same problem, Rezg et al. [7] found that it resulted in a complex analytical model with unrealistic assumptions compared to the simulation model which provided more flexibility and simpler estimations. Several studies have indicated the preference of simulation to optimise maintenance problems over analytical and mathematical approaches [8-11].

Although research on maintenance optimisation was established decades ago [12], the area of simulation-based optimisation in maintenance is becoming an emerging trend $[13 ; 14]$. Simulation has been traditionally used as a tool to understand and experiment with a system. However, connecting the simulation model to an optimisation engine ensures better and faster results. As illustrated in Figure 1-1, simulation based optimisation is an approach whereby an optimisation engine provides the decision variables for the simulation program. The simulation program will run the model and provide the results of the optimisation objective function. This process will continue iteratively between the simulation program and the optimisation engine until it results in a satisfactory solution or a termination due to prescribed conditions [15]. 


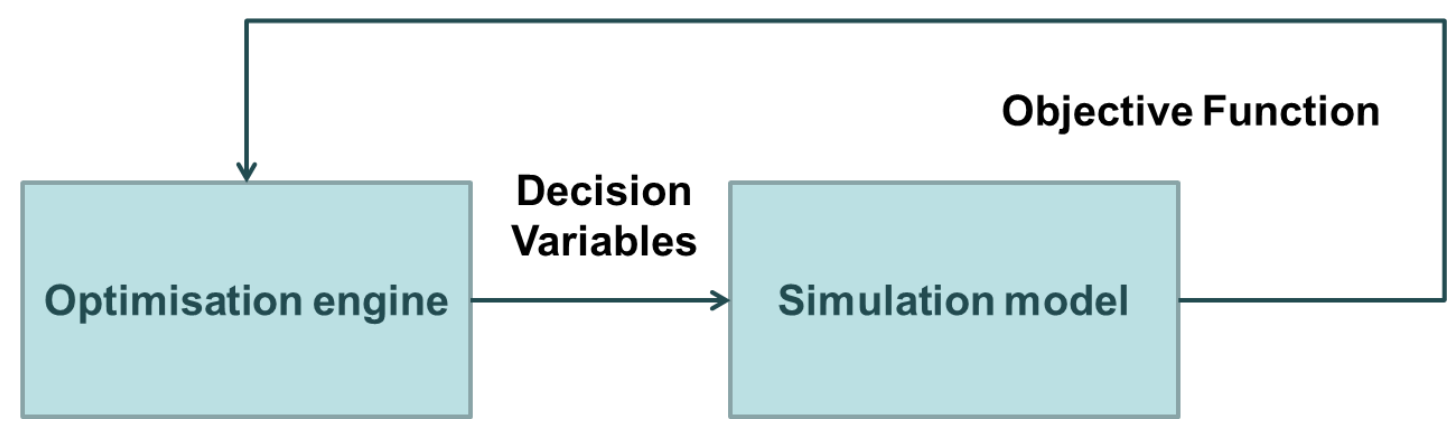

Figure 1-1 Simulation based optimisation approach

A considerable amount of literature has been published on maintenance simulation and optimisation. Dekker [12] provided a comprehensive view and analysis of maintenance optimisation models and applications. It is interesting to note that in his work, simulation has not been mentioned and the emphasis was on mathematical models only. More recently, Sharma et al. [13] observed that there is a potential as well as a growing interest amongst researchers to utilise simulation in optimising maintenance systems. The advancement in technology has enabled researches to use powerful computers and software with decreasing costs. Vasili et al. [16] review highlighted that it is becoming increasingly difficult to rely on static solution techniques to optimise maintenance systems and ignore the dynamic and stochastic nature of current business environments.

On the other hand, Andijani and Duffuaa [17] evaluated simulation studies in maintenance systems in terms of adherence to sound modelling principles such as program verification and validation. Alabdulkarim et al. [18] reviewed the applications of simulation in maintenance systems and categorised it according to the purpose of the study. Their research confirms that research on maintenance simulation is steadily rising. Additionally, they observed that research on the combined use of simulation and optimisation is limited.

Thus, this study provides an exciting opportunity to advance our knowledge on the state of art in the combined use of simulation and optimisation in maintenance systems. It is complementary to the earlier work of Alrabghi and Tiwari [19] which provided a summary description of the available literature on the same subject.

\section{Review Methodology}

This research aims to identify and summarise available literature on simulation-based optimisation of maintenance operations. Thus the scope is focused on research that includes simulating maintenance systems and connecting the simulation model to an optimisation engine. 
Research that focus on improving maintainability and reliability at the design stage is disregarded. There have been attempts to simulate maintenance operations through static system models, usually using Monte-Carlo simulation [1;9]. As time is a significant variable in maintenance operations, only attempts to model it through dynamic system models are within the scope of this research.

The research methodology of this review is similar to that of Alrabghi and Tiwari [19]. However, the search in this review is more comprehensive as it covers abstracts and keywords in addition to titles. Moreover, search in conference papers was limited to the last ten years only to capture recent work that is yet to be published in peer-reviewed journal papers.

A systematic research was conducted by searching for the following keywords in article titles, abstracts and keywords: (maintain* and optim* and simulat*) and (maintenance and optim* and simulat*). Scopus and Web of Science citation databases, two of the largest abstract and citation databases of peer-reviewed literature, were searched to identify the targeted papers. The Scopus search resulted in 15,001 documents in English whereas the Web of Science search resulted in 9,132 documents in English. An overview of the review methodology is shown in the figure below:

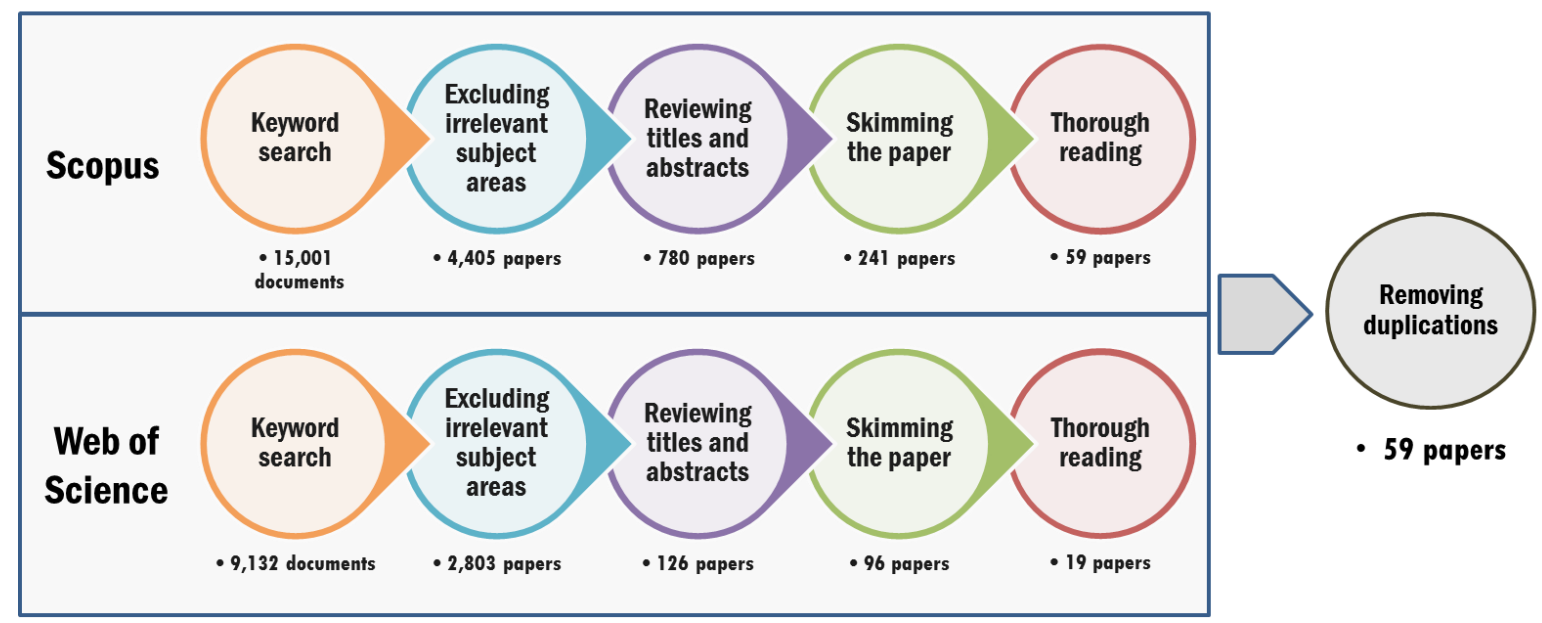

Figure 2-1 Systematic review methodology

The resulting documents were filtered in a systematic methodology as follows:

- Excluding irrelevant subject areas such as medicine, social sciences and arts and humanities. The main relevant subject areas are engineering, mathematics, decision sciences and business management. 
- Reviewing the titles and abstracts. This includes reading titles and abstracts and excluding papers that do not include simulation optimisation in maintenance.

- Skimming the whole paper to find out the application area as well as optimisation methods and simulation techniques. This was usually obtained by reading the methodology section of the paper.

A further comprehensive reading was conducted through the full documents which yielded 59 articles after removing duplications $[3 ; 7 ; 8 ; 11 ; 20-74]$. In order to classify the published literature and outline main trends in modelling and optimising maintenance systems, each paper was analysed to identify relevant features such as application area, maintenance strategies and policies, simulation modelling techniques and software, optimisation methods and software, optimisation objectives and decision variables. An abstract version of the analysis for all papers is shown in Appendix A.

\section{Overview of Reviewed Papers}

All the papers were published in the year 2000 or after with the exception of one journal paper published in 1982 [74]. Figure 3-1 shows an increasing trend in publications although it may not be statistically significant. These results match those observed in earlier studies, which found that the use of simulation in maintenance is increasing $[13 ; 14 ; 18]$. The resulting literature comprises of 47 journal articles (80\%) and 12 conference papers (20\%).

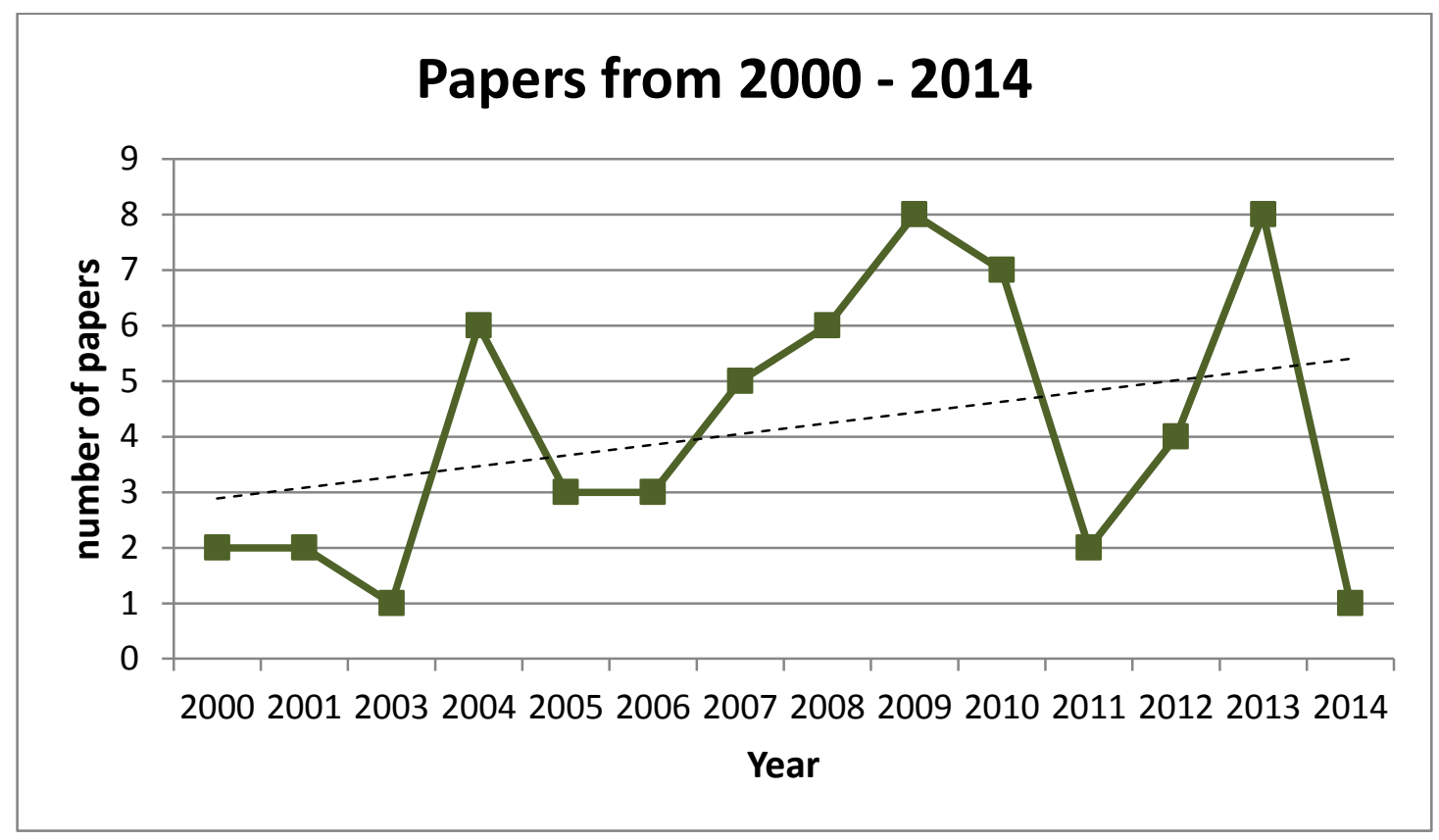

Figure 3-1 Number of publication by year $(2000-2014)$ (58 papers) 
The United States appears to be leading in this research field followed by France as illustrated in Figure 3-2. They both account for about two-fifth of the literature whereas ten countries account for the second two-fifths.

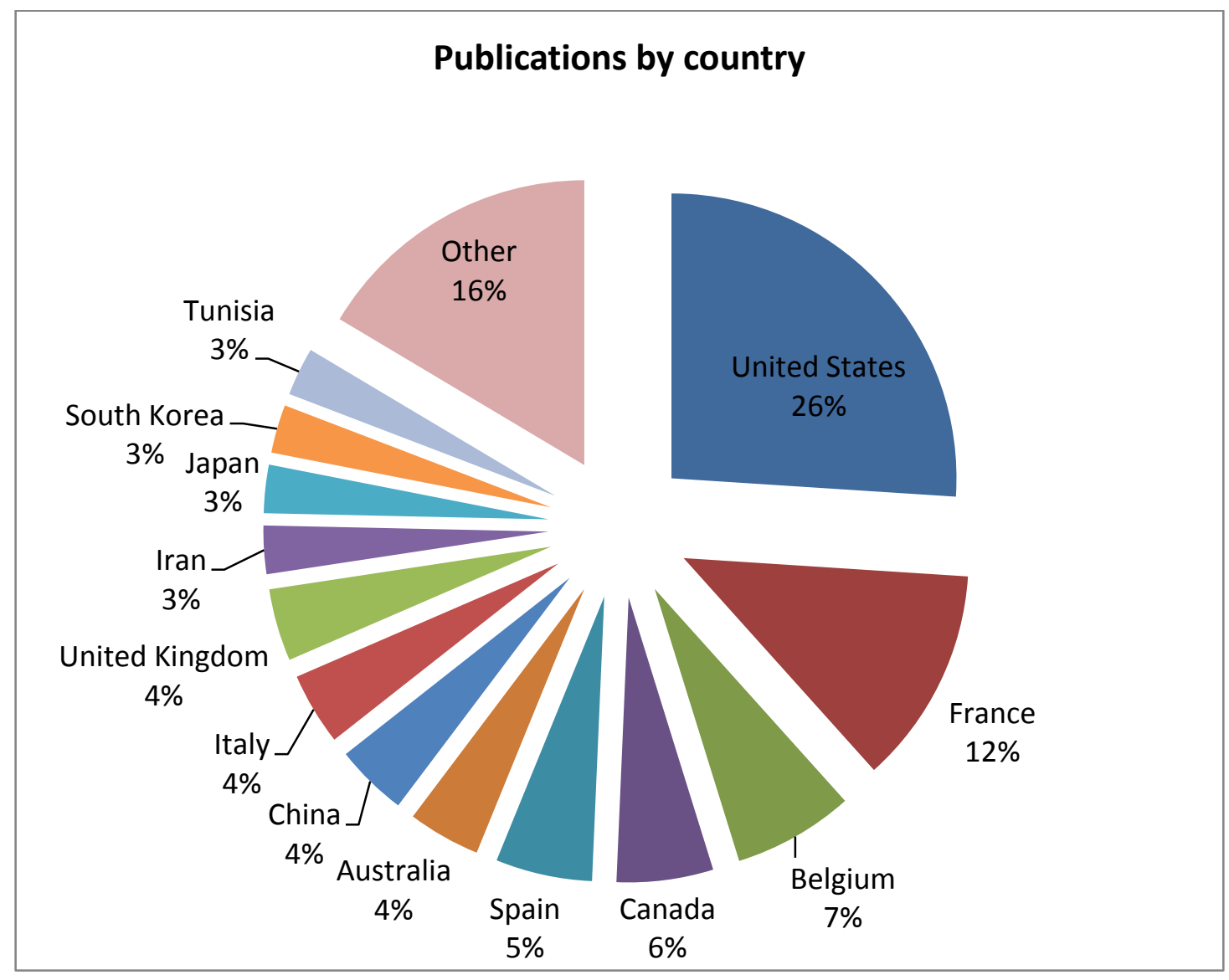

Figure 3-2 Publications by country (59 papers)

The most influential authors are shown in Figure 3-3. Rezg from Lorraine University in France was the most influential author publishing six articles which were cited more than 90 times. On the other hand, Allaoui and Artiba from University Lille Nord de France published only one article which was cited 88 times. It is interesting to note that the top four influential authors work in French research groups. In total, around 150 authors contributed to the field. Around half of them published articles which was cited only 5 times or less. 


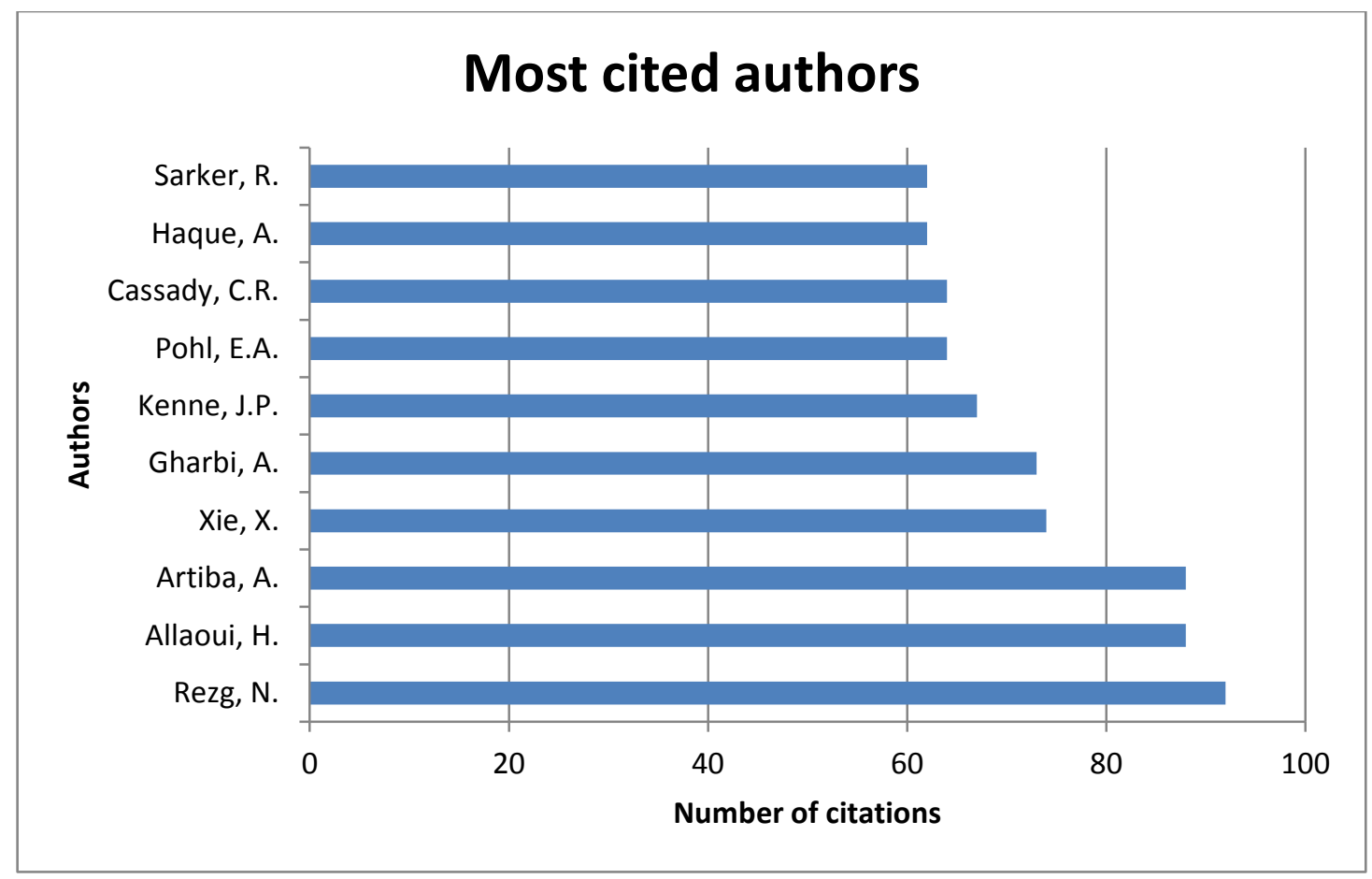

Figure 3-3 Most influential authors

The top publications sources are shown in Figure 3-4. The journal of Computers and Industrial Engineering published more than any other source. This can be explained by the Industrial engineering nature of the problems in the area, especially the side of simulating manufacturing systems and the applications of operation research. 


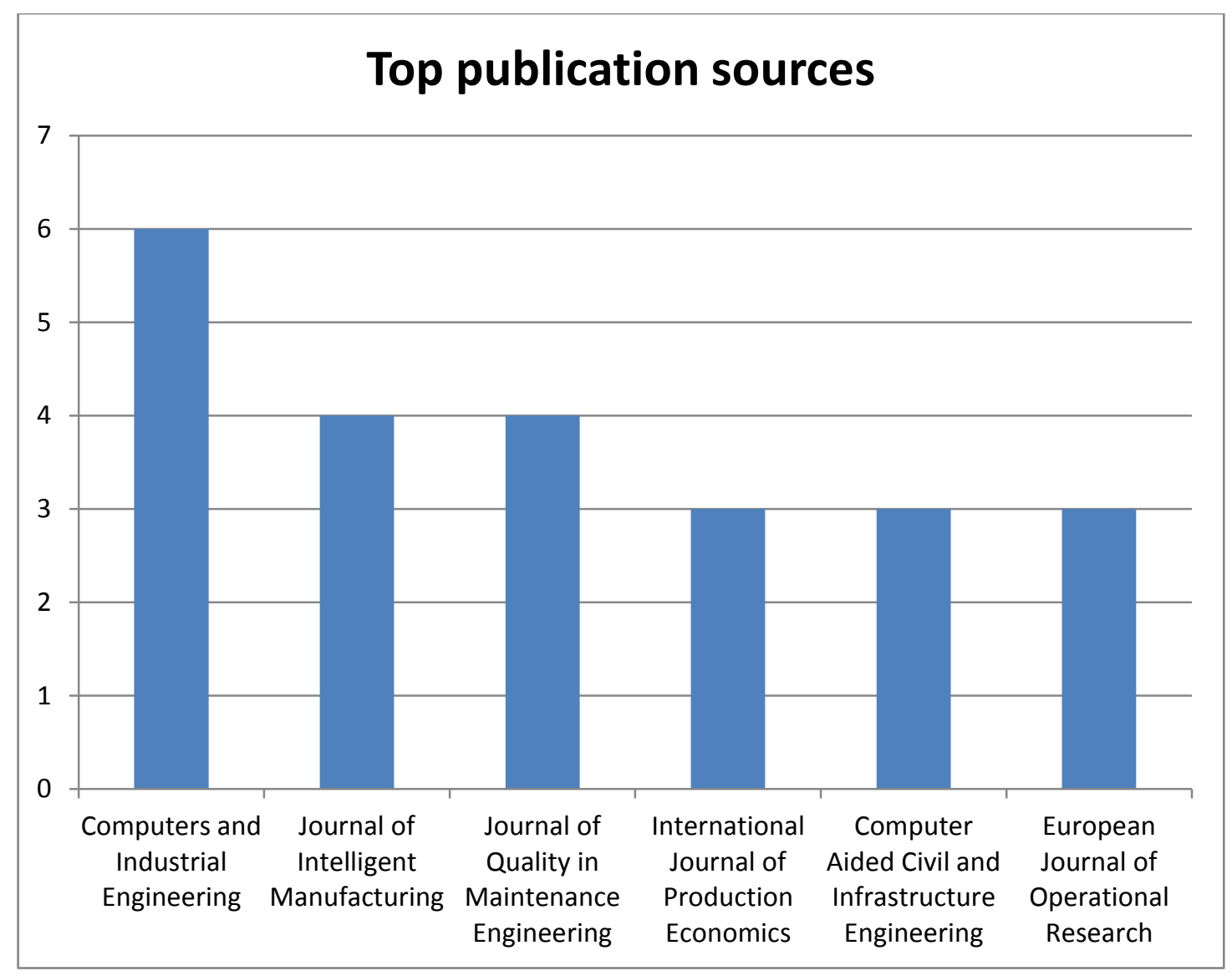

Figure 3-4 Top publications sources

Table 3-1 shows the most eight cited articles. It is interesting to observe that the top five articles are concerned with joint optimisation of maintenance and production or spare parts management.

Table 3-1 Top eight articles based on citations

\begin{tabular}{|l|l|c|}
\hline Publication & Title & Citations \\
\hline $\begin{array}{l}\text { Allaoui and } \\
\text { Artiba [11] }\end{array}$ & $\begin{array}{l}\text { Integrating simulation and optimization to schedule a hybrid flow } \\
\text { shop with maintenance constraints }\end{array}$ & 88 \\
\hline $\begin{array}{l}\text { Sarker and Haque } \\
\text { [72] }\end{array}$ & $\begin{array}{l}\text { Optimization of maintenance and spare provisioning policy using } \\
\text { simulation }\end{array}$ & 62 \\
\hline $\begin{array}{l}\text { Richard Cassady } \\
\text { et al. [73] }\end{array}$ & $\begin{array}{l}\text { Combining preventive maintenance and statistical process control: a } \\
\text { preliminary investigation }\end{array}$ & 55 \\
\hline Rezg et al. [67] & $\begin{array}{l}\text { Joint optimization of preventive maintenance and inventory control } \\
\text { in a production line using simulation }\end{array}$ & 47 \\
\hline $\begin{array}{l}\text { Gharbi and } \\
\text { Kenne [64] }\end{array}$ & $\begin{array}{l}\text { Maintenance scheduling and production control of multiple- } \\
\text { machine manufacturing systems }\end{array}$ & 46 \\
\hline Yao et al. [3] & $\begin{array}{l}\text { Optimal preventive maintenance scheduling in semiconductor } \\
\text { manufacturing }\end{array}$ & 46 \\
\hline Yang et al. [54] & $\begin{array}{l}\text { Maintenance scheduling in manufacturing systems based on } \\
\text { predicted machine degradation }\end{array}$ & 40 \\
\hline Ng et al. [44] & Optimal long-term infrastructure maintenance planning accounting & 37 \\
\hline
\end{tabular}




\subsection{Application areas}

Case studies were conducted in semiconductor manufacturing systems [3;35; 37], electricity sector [39; 70] automotive industry [52; 57; 58], plastic industry [56], transportation infrastructure $[41 ; 44 ; 49 ; 62 ; 68]$ and train maintenance facilities $[34 ; 50]$. It is however important to note that most researchers tended to use academic case studies. See for example: $[7 ; 11 ; 40 ; 43 ; 45 ; 48 ; 51 ; 72]$.

While most studies examined maintenance in a production context, few researchers examined maintenance operations for working products such as ships or aircrafts. The low number of published papers on military hardware might be due to the potentially sensitive nature of these systems. Johansson and Jagstam [36] suggested an approach to provide decision support for maintenance planning intended for military equipment while Gupta and Lawsirirat [8] analysed the strategic optimal maintenance actions for a general multicomponent system whose health is monitored in real time. Both studies reported the shift towards product service system as the main motivation for their research. El Hayek et al. [63] demonstrated the effectiveness of simulation based optimisation for planning maintenance operations for an aircraft gas-turbine. It is observed that there are several differences between maintenance in a production context and maintenance in a product service system context. In the former issues such as bottle necks, buffer size and parts waiting in progress have an impact on maintenance planning. In contrast, logistics and transportation are main issues in product service systems.

As observed by Goti et al. [56] and Horenbeek et al. [75], little research is directed towards optimising a system composed of several equipment and most of the research focused on optimising single equipment without considering the production configuration. Indeed, systems compromising of a single machine producing a single product [48] or two exactly identical machines $[42 ; 46]$ are oversimplified and do not reflect the complexity and interactions in real manufacturing systems.

\subsection{Maintenance strategies and policies}

Maintenance strategies can generally be categorised into Corrective Maintenance (CM), Preventive Maintenance (PM) and Condition Based Maintenance (CBM). As illustrated in Figure 3-5, CM occurs when the asset breaks down resulting in unexpected shutdown and 
high maintenance cost. PM is scheduled in order to minimise the impact of a sudden breakdown. PM usually consumes fewer resources compared to $\mathrm{CM}$ and can be accommodated in the production plans. In fact PM can be as simple as cleaning filters, lubricating and changing oil preventing a failure of a critical a component that is costly and takes time to be delivered. Because the operation schedules and environment change dynamically in the real world, PM can take place unnecessarily. To ensure PM occurs only when needed, CBM was introduced. This can be either in a form of regular inspections to evaluate the assets' wear or in the form of sensors streaming data to diagnostic software. Therefore maintenance tasks can be triggered only when the wear reaches a certain level. It is worth mentioning that CBM is sometimes included under the branch of PM [76].
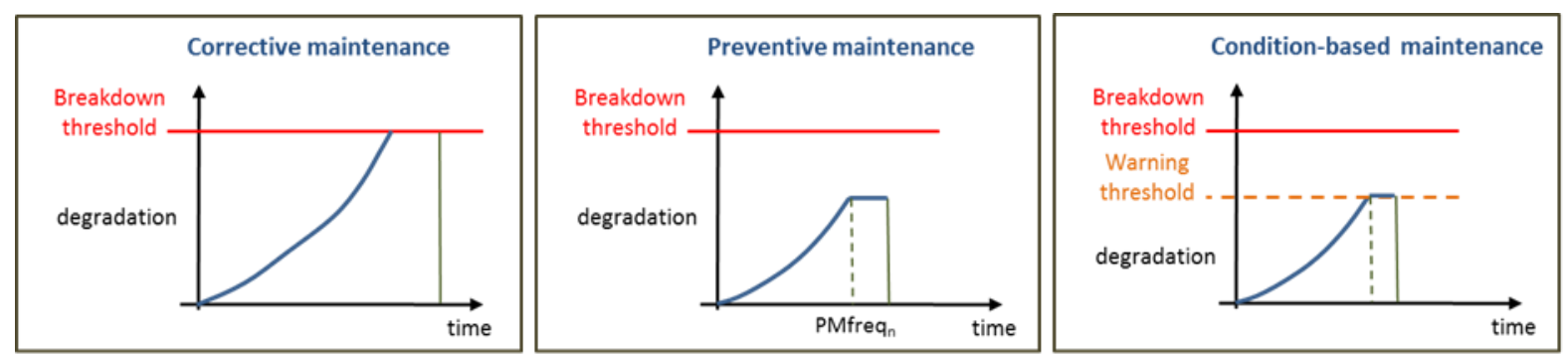

Figure 3-5 Overview of maintenance strategies in the literature

The majority of researchers investigated PM as can be seen from Figure 3-6. This includes policies such as time-based $[51 ; 72]$ where PM is scheduled every $\mathrm{x}$ units of time or agebased $[7 ; 61]$ where PM is scheduled every $x$ units of operating time. Other variations of preventive maintenance policies include group block replacements for unrepairable systems where components will be replaced if it fails whereas all other components in the system will be replaced at predetermined interval and combined block replacements where all components will be replaced at predetermined intervals but if a component fails, it will be replaced as well as all components in an operation state [51]. 


\section{Maintenance types in the literature}

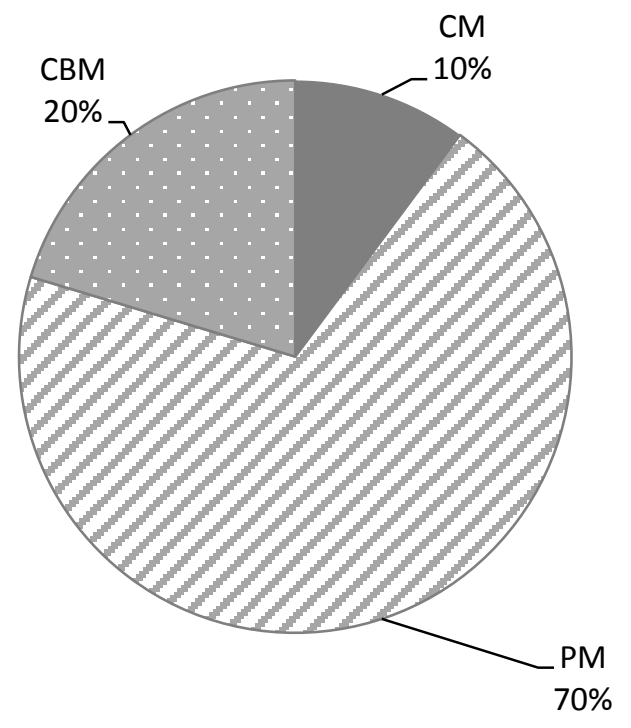

Figure 3-6 Maintenance types in the literature

CBM received less attention perhaps because it is relatively new. However, sensors are becoming lower in terms of cost which is encouraging the implementation of Condition Based Maintenance [32]. CBM is becoming increasingly popular especially in Product Service Systems or long-term services agreement where sensors are installed on products to monitor degradation [8]. Periodic inspections are an alternative to sensors but its frequency has to be optimized as it will consume resources and affect performance [70]. Horenbeek and Pintelon [29] investigated prognostic maintenance which is essentially CBM combined with the ability to predict the deterioration of components in the system to see if it is expected to reach the threshold before the next scheduled inspection; If it does then it is replaced immediately. Although the applications of CBM are increasing in the industry [77], it is evident that it is poorly covered in the literature.

Opportunistic maintenance is a policy relevant particularly in situations where down-time is very costly and a shut-down can be exploited to perform other maintenance actions. Murino et al. [46] examined opportunistic maintenance in a continuous production system where stopping one machine could mean bringing the whole production system to a halt. Shenfield et al. [39] examined a fleet of aero-engines where unscheduled maintenance results in cancelled flights and losing customers. 
In reviewing the literature, only limited effort was found to be directed towards comparing different maintenance strategies and policies. Xiang et al. [32] and Yang et al. [54] studied a repairable system where preventive maintenance and condition-based maintenance policies were investigated. The focus of Allaoui and Artiba [11] research was on evaluating the effect of various priority rules and heuristics on maintenance scheduling. Horenbeek and Pintelon [29] compared the effect of five different maintenance strategies on one machine, namely CM, block based PM, age based PM, inspection based CBM and CBM with continuous monitoring.

However, on the whole the research is limited in terms of covering main maintenance decisions such as comparing and selecting the optimum maintenance policies in multicomponent systems and determining the optimum maintenance resources. In particular, investigating the implications of implementing new CBM strategies in manufacturing systems compared with traditional PM policies. In addition, there is a potential of evaluating heuristics against priority rules set by various optimisation algorithms.

\section{Simulating and Modelling Maintenance Systems}

\subsection{Modelling maintenance systems}

It is interesting to observe that the scope of the maintenance models varied significantly in the literature. The main themes are presented in Figure 4-1. For instance, Gupta and Lawsirirat [8] modelled only the assets deterioration, Sarker and Haque [72] added maintenance resources such as spare parts management and Arab et al. [22] added production dynamics such as buffer capacity. The decision of including an element should depend on the level of effect it has on the desired simulation output [78]. Although maintenance resources such as technicians, spare parts and equipment have a direct effect on maintenance cost and scheduling [6; 79; 80], only few researchers incorporated them in the simulation model. In fact, the assumption of readily available maintenance resources is fairly common $[7 ; 11 ; 22 ; 27 ; 51]$. 


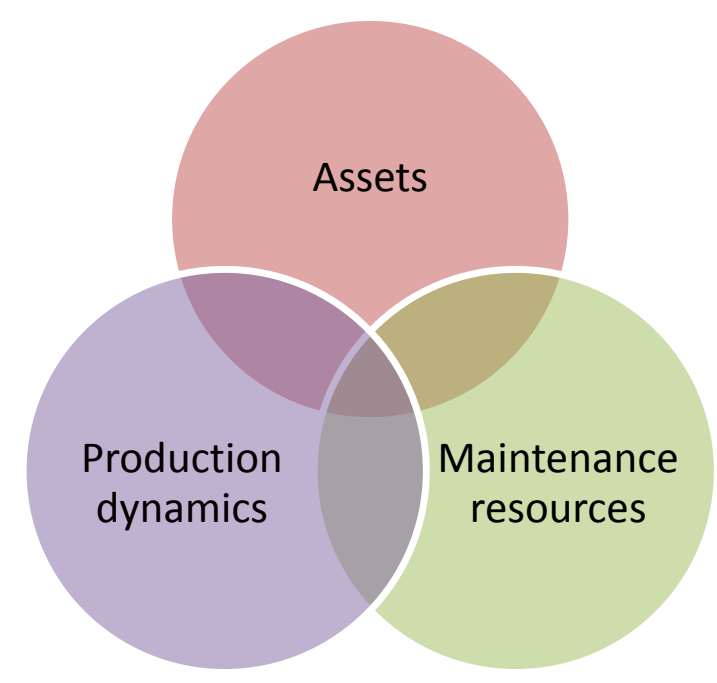

Figure 4-1 Scope of maintenance simulation models in the literature

Three main levels of modelling assets details are observed in the literature. The majority of researchers modelled assets as a whole unit. Therefore, the deterioration, failure and interaction on a subsystem or a component level is not modelled in the simulation. On the other hand, some researchers modelled machines as subsystems. Oyarbide-Zubillaga et al. [52] modelled assets as subsystems based on types of maintenance activities such as electric/electronic and hydraulic subsystems. Zhou et al. [31] optimised maintenance for sub-systems connected in series considering the economic dependency, where carrying maintenance tasks in groups cost less or more than carrying it individually. Horenbeek et al. [29] modelled only one subsystem in several machines considering economic, structural and stochastic dependencies. In a more detailed modelling of assets, Roux et al. [51] evaluated three maintenance policies for a system comprising of two independent components. Sarker and Haque [72] optimised maintenance and spare part provisioning policy for 13 identical and independent components.

Gupta and Lawsirirat [8] highlight the fact that meaning of the term 'component' differs depending on the context. It is not possible to model a complex system comprising of thousands parts for practical constraints. Therefore it is proposed to consider the components that have significant impact on the asset performance. Tools such as Failure Modes and Effects Analysis (FMEA) that utilise historical maintenance data can be used to identify the most critical components.

Modelling identical units while assuming there are no dependencies between them is one of the assumptions researchers consider to simplify the maintenance system. Other relaxing assumptions include: 
- Perfect inspections: inspections reveal instantly the real deterioration state of the asset

- Perfect maintenance: maintenance job is done perfectly from the first time and there is no chance of misdiagnosis. It is often referred to as 'machines are as good as new' after maintenance actions

- Duration of maintenance actions is constant and sometimes is totally neglected implicating an instantaneous maintenance

- Costs of all maintenance actions are known and constant. Furthermore, cost of CM is always higher than PM

- Maintenance resources such as spare parts, tools and technicians are always available immediately when needed

- Failures are detected instantaneously,

Perhaps the most significant aspect is the modelling of machine aging process. Some researchers simplified it by designing only two states for the machine, either working or broken [56]. Additionally, the machine is regarded as good as new after undertaking maintenance tasks. On the other hand, El Hayek et al. [63] considered an improvement factor that incorporates imperfect maintenance. Therefore the machine status after maintenance tasks will not be regarded as good as new, rather it lies somewhere between a broken machine and a new machine depending on the random improvement factor. Furthermore, the duration between preventive maintenance tasks is reduced as the machine ages. To schedule PM, Ramírez-Hernandez et al. [37] modelled a PM window constituting of warning date which is the earliest time a PM can be conducted, due date which is the suggested date for PM and late date which is the latest time to conduct PM.

Accurate modelling of machine degradation process becomes essential for examining condition-based maintenance where an inspection is conducted periodically to decide which maintenance tasks should be executed [77]. Alternatively, sensors could provide indicators on machines' health such as vibration magnitude and temperature in real time [32]. When indicators' reading exceed a specific threshold, a maintenance task is triggered. Guizzi et al. [45] simulated condition based maintenance via discrete event simulation. In their study, the limitation of discrete event simulation is overcome by triggering special events that increase the machine wear at predetermined intervals.

\subsection{Simulation techniques}


Discrete event simulation (DES) dominates the literature as it was used alone or combined with other modelling techniques by around two thirds of researchers (see Figure 4-2). This should not come as a surprise since it is the most popular technique in modelling manufacturing systems including production planning, maintenance and inventory management [81]. DES is the modelling of a system in which variables' state change at specific points in time. Thus, the system is modelled by arranging these changes (called events) in a chronological order and the system is updated whenever an event occurs. However, between events, the system remains unchanged and time is advanced to the next scheduled event [82].

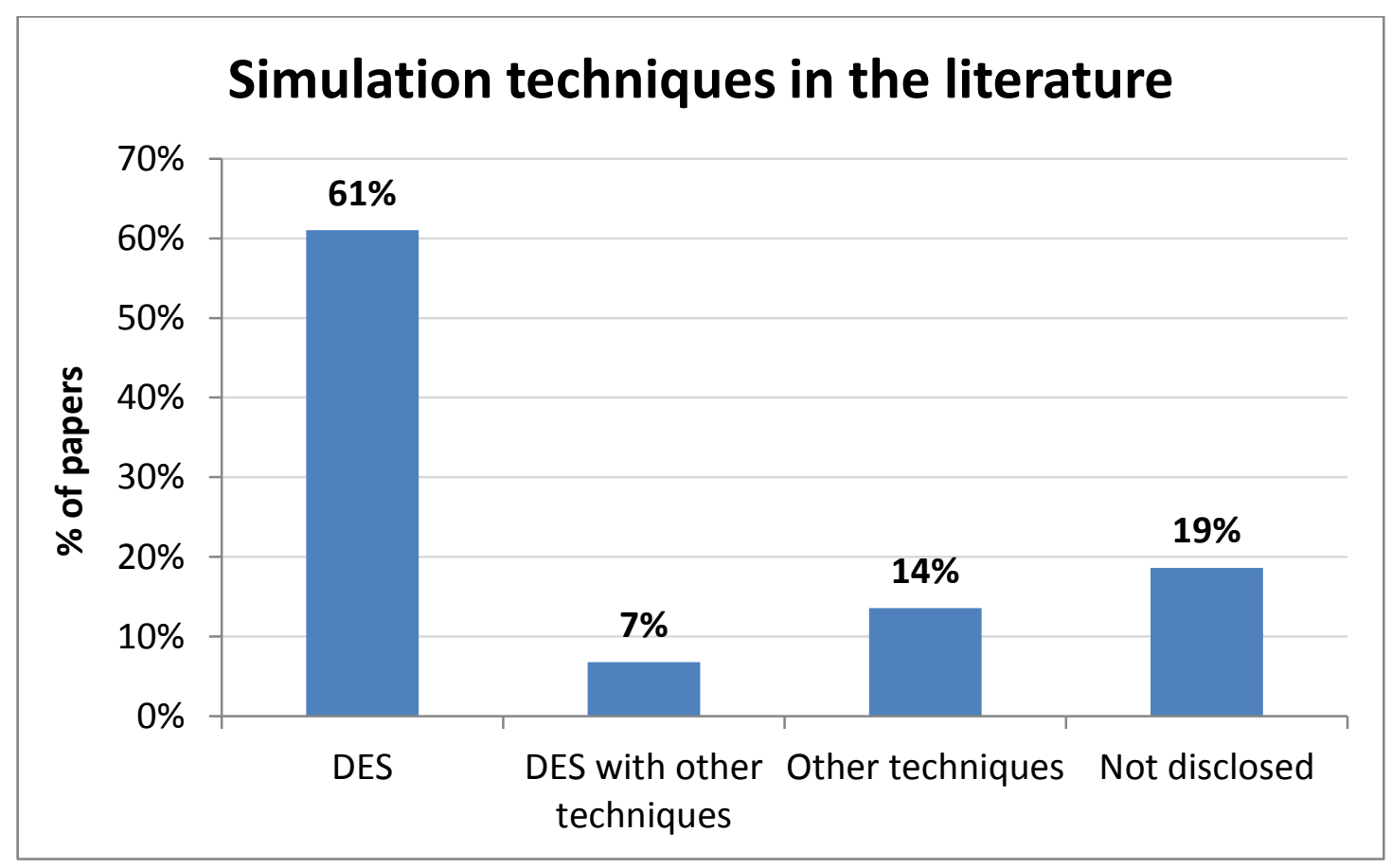

Figure 4-2 Simulation techniques in the literature (59 papers)

Most DES studies utilised process-based specialised simulation software that provide graphical user interface such as Arena $[45 ; 46 ; 50 ; 55 ; 58 ; 61 ; 63$ ] which is offered by Rockwell Automation, Promodel $[7 ; 22 ; 60 ; 67]$ which is offered by Promodel Corporation and Witness $[25 ; 52 ; 57]$ which is an offering of Lanner Group. Other DES studies utilised general-purpose programs and languages such as C++ [44; 71], Java [43], Matlab [48] and Excel [47]. Specialised simulation software provide several advantages over general-purpose programs such as rapid modelling, animation, automatically collected performance measures and statistical analysis [82].

Some researchers developed a hybrid model combining DES with other modelling techniques to gain further advantages. Alrabghi and Tiwari [25], Xiang et al. [32] and Gharbi 
and Kenne [64] built a discrete event model to represent the general manufacturing system with the machine degradation process modelled as a continuous element to reflect the fact that machines age as time passes by.

On the other hand, simulation techniques other than DES were reported in some articles. This includes agent-based simulation $[24 ; 28 ; 38]$ and continuous simulation $[8 ; 41]$.

It is worth mentioning that a considerable number of researchers did not disclose the simulation technique or the software used in the research. This surprisingly includes some recent publications (see for example: $[30 ; 31 ; 36]$ ). Therefore it might not be possible for an independent researcher to replicate the experiments. In contrast to Andijani and Duffuaa [17] findings, this study confirms that neglecting the simulation technique or language is present in the literature.

\section{Optimising Maintenance Systems}

\subsection{Optimisation methods}

The results obtained from the analysis of optimisation methods in the literature are shown in Figure 5-1. Similar to simulation techniques, not all researchers disclosed the optimisation methods they used $[3 ; 31 ; 37 ; 72 ; 74]$. Manual optimisation was reported in several articles where simulation runs are conducted systematically while manually changing variables values in gradual steps, see for example: $[7 ; 40 ; 42 ; 66]$. As can be expected, a serious weakness with this approach is its limitation in terms of exploring the search space and number of variables. 


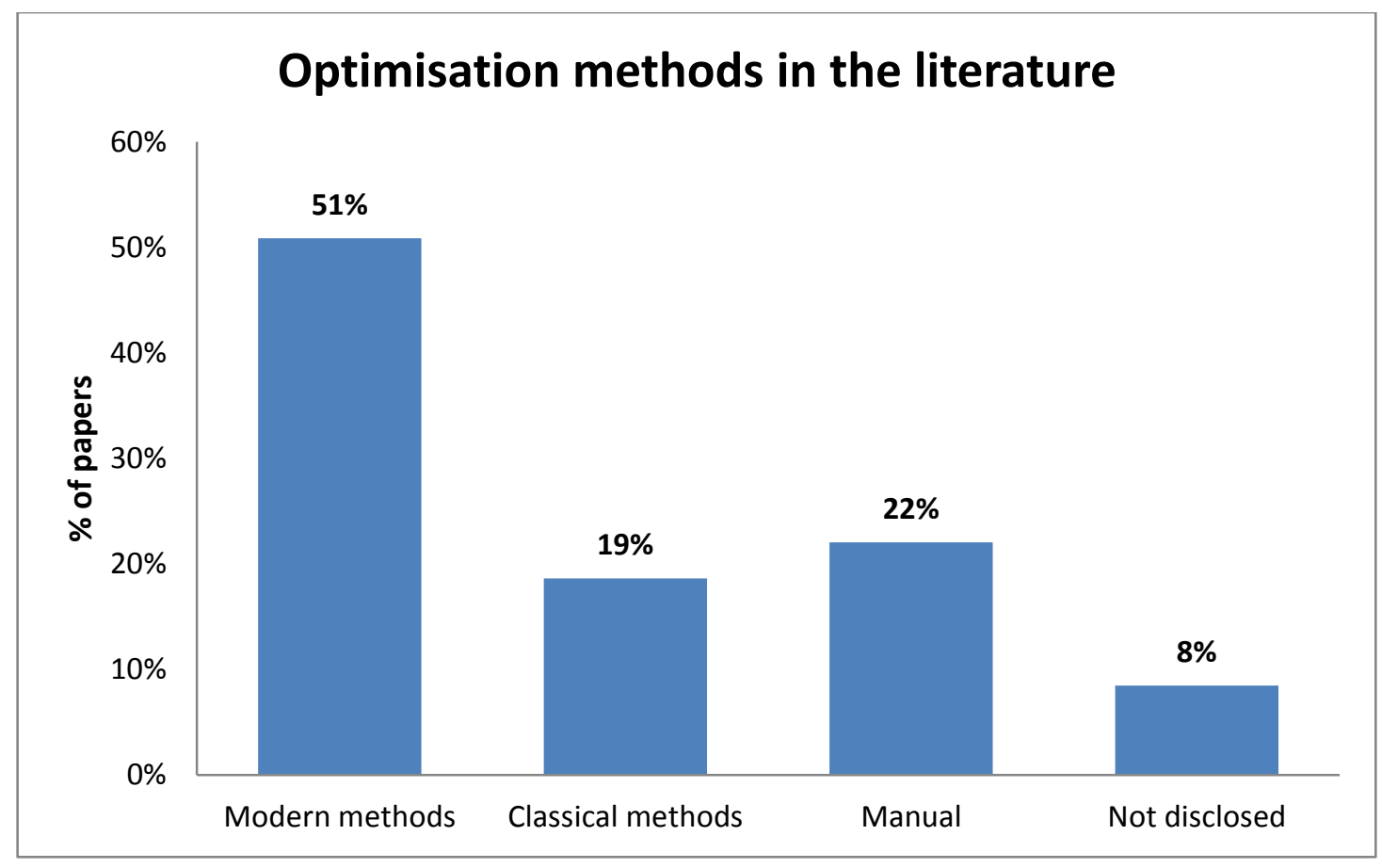

Figure 5-1 Optimisation methods in the literature (59 papers)

On the other hand, classical optimisation methods [83] that are analytical and utilise differential calculus to find the optimal point such as scatter search [61], Nelder-Mead method [27; 51], cyclic coordinate method [32], the modified powell method [69], Fibonacci algorithms [20] and simple local search [8; 24] were applied to simple manufacturing systems. One criticism of much of the literature on optimizing maintenance by classical methods is the lack of analysis of the objective function and the solution space. Therefore the justification and proper selection of the optimisation method is sometimes absent.

As the complexity of maintenance systems increased [4; 14], modern optimisation methods were utilised as they are more capable of dealing with complex problems [83; 84]. Most of these methods are based on selected behaviours found in nature and sometimes referred to as non-traditional methods. As shown above in Figure 5-1, modern optimisation methods were utilised in around half of the papers becoming the most reported optimisation approach. The pie chart below shows the breakdown of modern optimisation methods in the literature. It is apparent from this pie chart that only two modern optimisation methods were applied namely Genetic Algorithms (GA) and Simulated Annealing (SA). In fact only few articles reported the use of SA. This reflects an opportunity to research the suitability of other modern optimisation methods to maintenance problems. 


\section{Modern optimisation methods in the litrature}

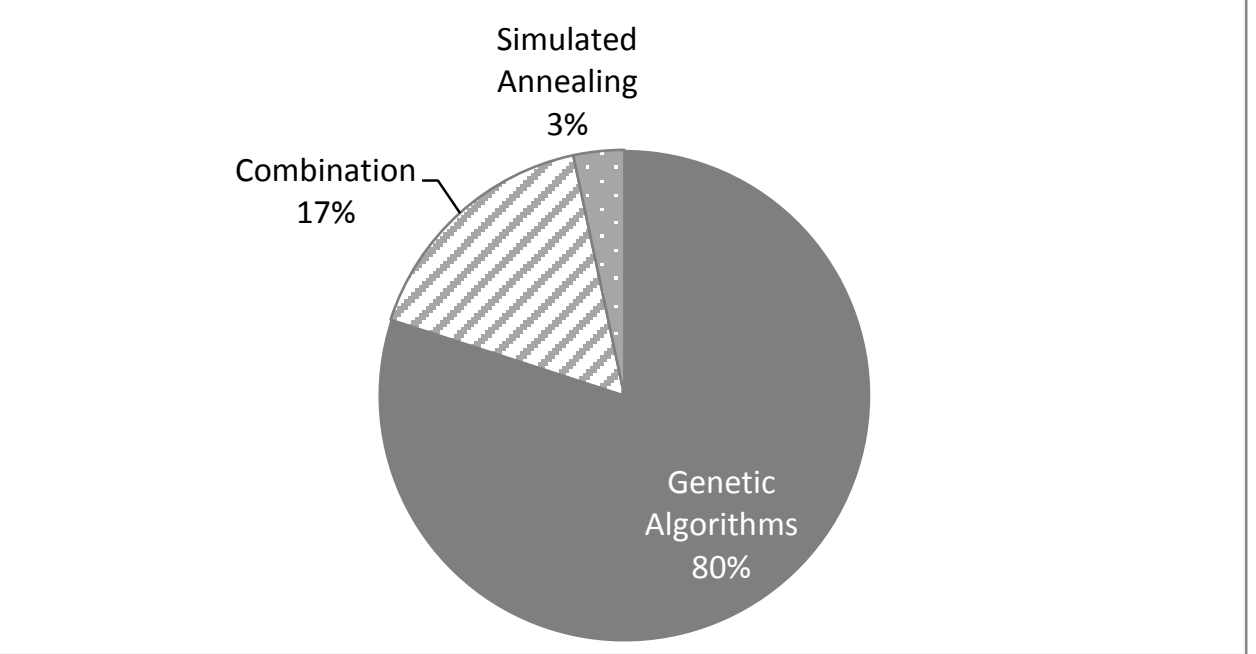

Figure 5-2 Breakdown of the modern optimisation methods in the literature (33 papers)

It can be seen that by far the most reported modern optimisation method is GA. It is based on the process of natural selection in biology and it has been applied successfully to a wide variety of practical optimisation problems [83]. In addition, it is well suited for complex simulation based optimisation where there is no prior knowledge of the response surface typology [85; 86].

SA comes from the concept of the annealing process in metallurgy to harden metals. Metals are melted in high temperature at the start and then cooled gradually in a controlled environment to obtain desired attributes. It can be used to solve various types of problems including continuous, discrete and mixed-integer [83].

Guuizzi et al. [45] and Murino et al. [46] approach has a significant advantage. In their study they utilised OptQuest, a specialised optimisation tool that allows the utilisation of multiple optimisation algorithms including tabu search, scatter search, integer programming, and neural networks. On the other hand, Ali et al. [55] utilised different optimisation algorithms included in the Intelligent System for Simulation and Optimisation software (ISSOP) such as component wise enumeration, quasi gradient strategy and GA. Yun et al. [30] conducted a two steps optimisation process where both GA and SA are used respectively.

Figure 5-3 shows how optimisation methods were utilised in different maintenance strategies. The use of modern methods and classical methods is comparable in both CBM and PM strategies. However, manual optimisation was used in less than $10 \%$ of CBM systems compared to around $20 \%$ in PM systems. Optimising CM systems appears to follow a different pattern where modern methods and classical methods were utilised equally. 


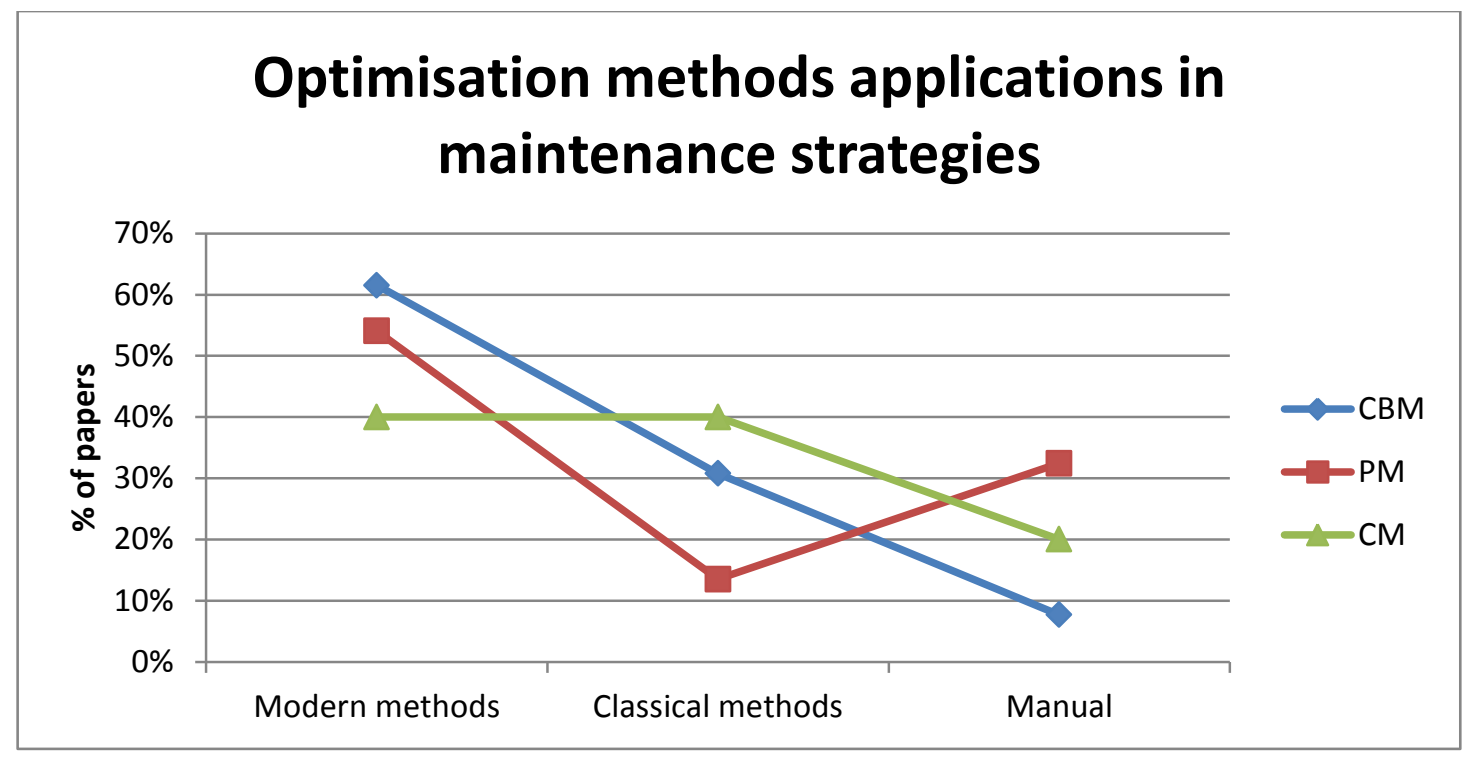

Figure 5-3 Optimisation methods application in maintenance strategies

Very limited research was conducted to compare the performance of multiple optimisation algorithms. Dridi et al. [53] compared three different variations of GA: Island Genetic Algorithm (IGA), Non-dominated Sorting Genetic Algorithm-II (NSGA-II) and Niched Pareto Genetic Algorithm 2 (NPGA-2) on a pipe renewal system. They concluded that the algorithms performance varies based on the size of the pipe network. On the other hand, Alrabghi et al. [25] compared SA with Hill Climb and Random Solutions. They found that SA achieved better results although its computation time was relatively high.

\subsection{Problem formulation for optimisation}

An optimisation problem can be described by three main elements: design variables, constraints and objective functions. Each will be discussed in details in the following sections,

\subsubsection{Optimisation objectives}

Minimising cost was reported as an objective in more than $70 \%$ of the studies (see Figure 5-4). Machines and equipment can be over-maintained which increases preventive maintenance cost or under-maintained, increasing failure rate and its consequences. Usually reactive maintenance is fixed at a higher cost than preventive maintenance and the objective is to minimise the total maintenance cost [8;32; 51]. Arab et al. [22] correctly argues that maintenance is a part of the manufacturing system and considering maintenance cost alone is not sufficient. To counter that, some researchers developed an objective function that encompasses the total system cost. This might include a penalty for 
each time unit a machine is unavailable [25; 70], the cost of defective products [52], a penalty for not meeting demand $[66 ; 67]$ or spare parts management costs $[58 ; 72]$.

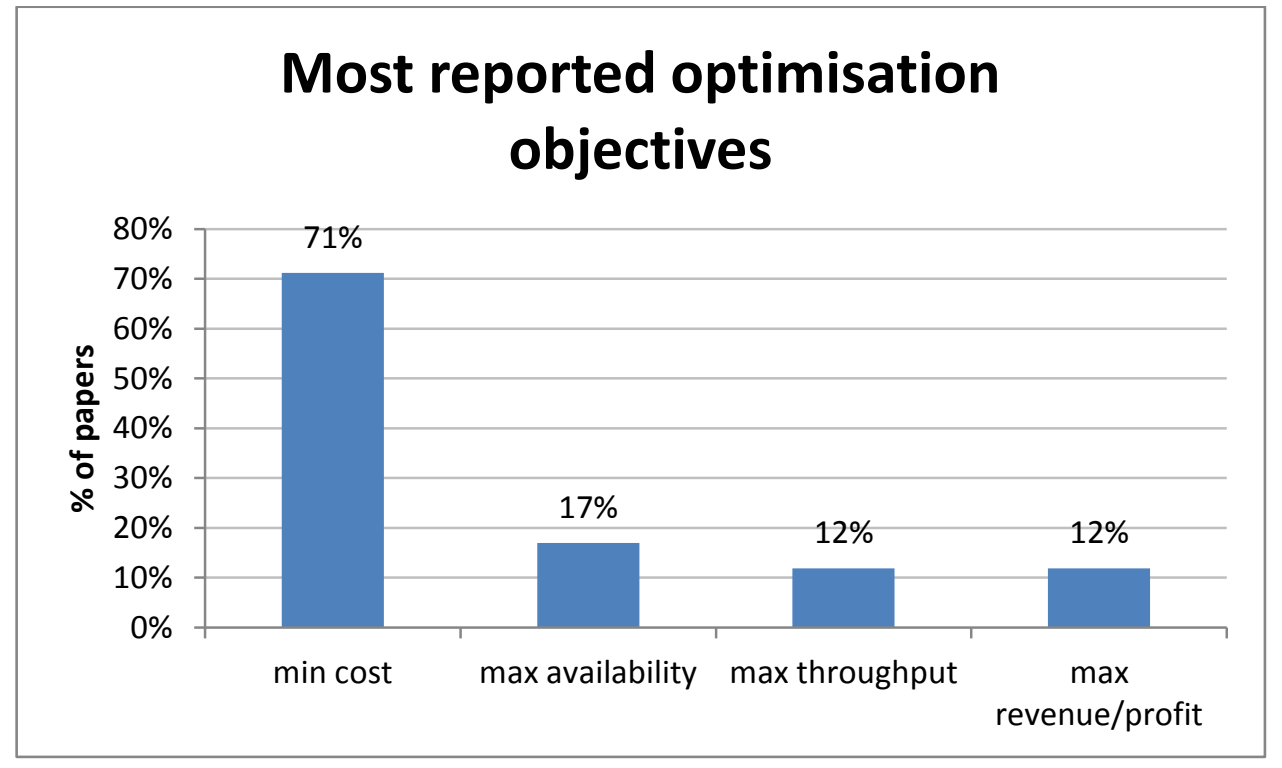

Figure 5-4 Most reported optimisation objectives (59 papers)

Instead of maintenance cost, Roux et al. [27] identified maximising machines availability as the optimisation objective. They argue that it is more appropriate as production costs are much higher than maintenance costs. Such explanation tends to overlook the fact that maintenance costs are significant [3] and can be higher than production costs [1]. Similarly, Boulet et al. [42] maximised availability and maintenance costs were considered manually for each case after the optimisation results.

However, maximum machine availability does not necessarily lead to maximum production throughput in manufacturing settings, which is an optimisation objective in several recent studies $[22 ; 37 ; 40 ; 55]$. A machine can be available but not in working state due to many reasons such as shortage of raw material or blockages as a result of bottle necks. Therefore it is suggested to consider the manufacturing system as a whole and maximise the production throughput.

In addition to minimising costs, maximising availability and maximising production throughput, other optimisation objectives were identified in the literature. OyarbideZubillaga et al. [52] considered a more holistic approach where the total cost and profit of the system is evaluated. The costs of maintenance tasks as well as defective products contribute to the cost function whereas the profit is calculated by the number of nondefective items produced. The variation in selecting the optimisation objectives might be due to the nature and purpose of the study. For instance, Ramírez-Hernandez and Fernandez 
[35] formulated the optimisation objective purely on production measures namely to minimise both machine cycle time and wait in progress. The purpose of study could have been to support a quality initiative without a particular interest in cutting maintenance resources in the factory. On the contrary, Hani et al. [50] examined a train maintenance facility where the focus was on minimising the parts immobilization time as well as minimising occupation rates for maintenance workshops. Nevertheless, limited discussion of the optimisation objectives choice was apparent in the literature.

Similar to the situation in many engineering problems [87], maintenance systems might require optimising several objectives simultaneously such as minimising maintenance costs and maximising assets availability. It is observed that researchers used one of the following approaches to solve that:

- Including multiple objectives in one objective function. For example, calculating machine downtime as costs $[25 ; 70]$ or including a penalty for not meeting demand in the cost function [66; 67]. However, a challenge with this approach is transforming an objective in another objective's unit. For example, estimating how much unavailability of certain equipment would cost or estimating how costly it is to fail to meet the demand. Moreover, these costs are likely to change depending on the market dynamics [29].

- Developing a desirability function where optimisation objectives are assigned weights according to its importance to the decision maker to reach the best compromise $[42 ; 43 ; 62 ; 69]$. This approach does not require transforming an objective in another objective's unit. Nevertheless, it forces the decision maker to trade-off between objectives by assigning weights and ultimately producing a single result.

- Utilising multi-objective optimisation algorithms that have the ability to solve multiple objectives simultaneously. For instance, Non-dominated Sorting Genetic Algorithm was implemented to minimise costs and maximise profits [52;56; 57]. It is interesting to note that only a limited number of researchers utilised multi-objective optimisation as shown in Figure 5-5. 


\section{Single-objective vs. multi-objective optimisation}

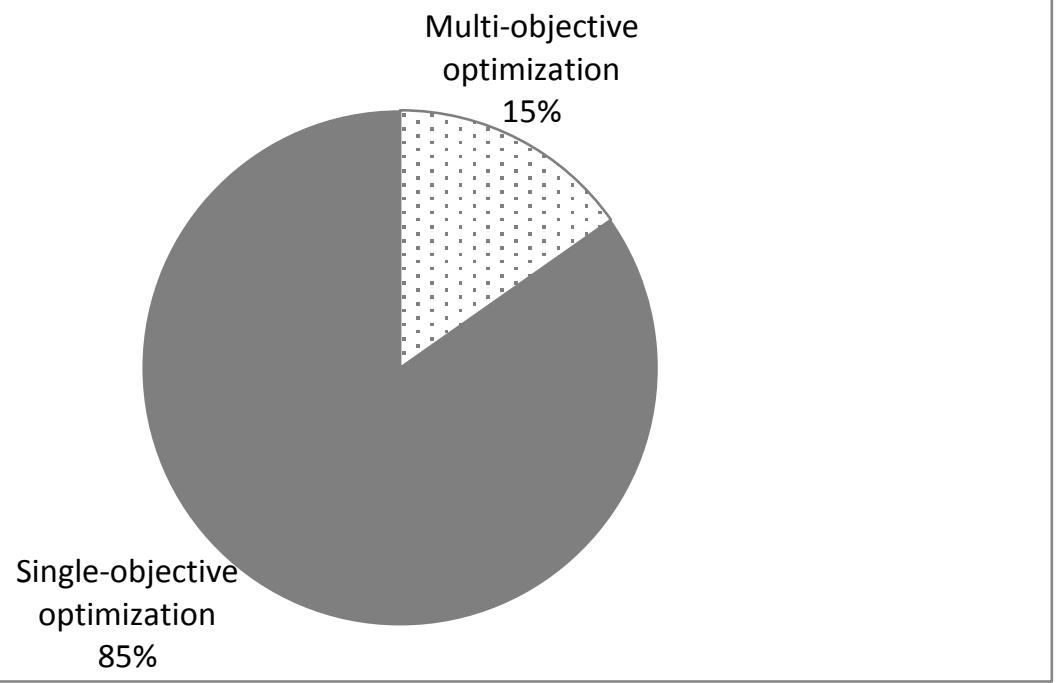

Figure 5-5 Single-objective vs. multi-objective optimisation (59 papers)

\subsubsection{Decision variables}

Five decision variables were identified as the most reported in the literature as illustrated in Figure 5-6. Determining how frequent should assets be maintained to achieve the best possible solution is a continuing concern within the field. It is the most obvious option in cases where PM is modelled in the system as it can be controlled and its effect on cost and availability is widely accepted.

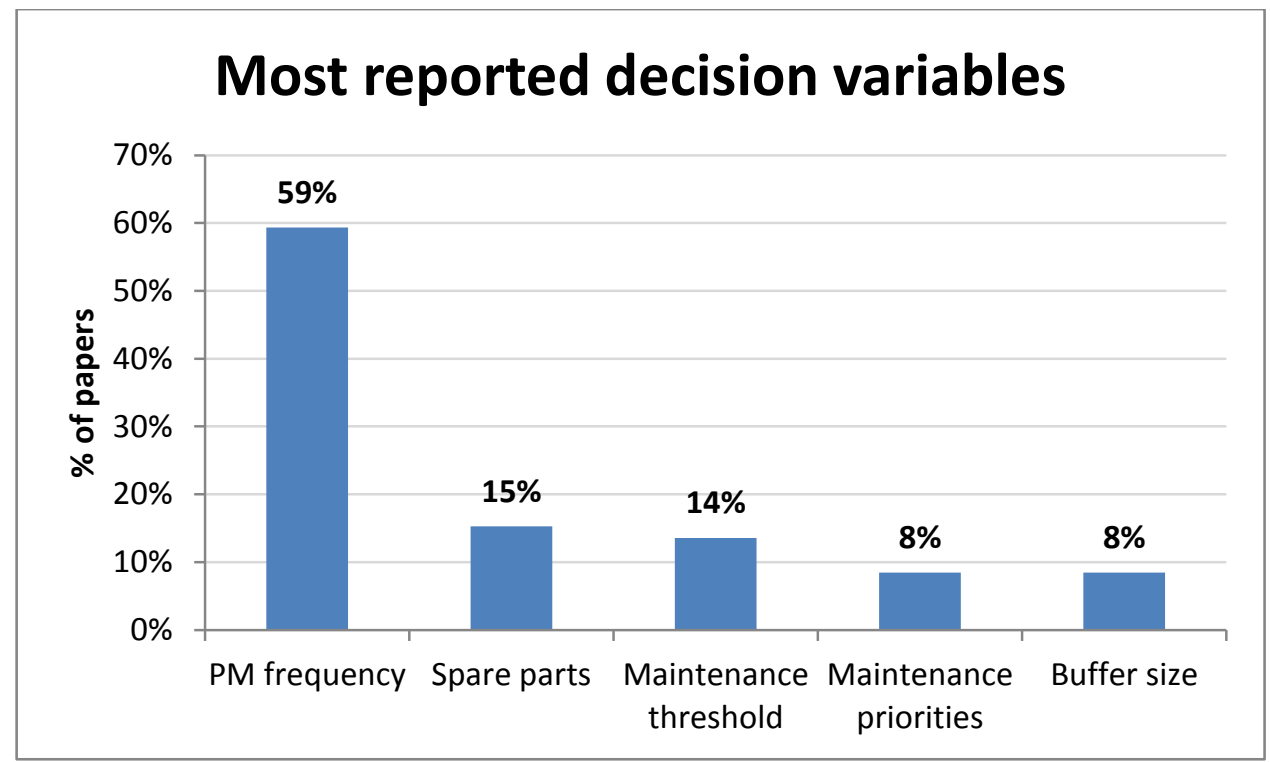

Figure 5-6 Most reported decision variables in the literature (59 papers) 
However, when the system in interest incorporates CBM [29; 32; 45] or opportunistic maintenance $[31 ; 39]$, the obvious decision variable becomes the maintenance threshold that triggers maintenance actions. If information on assets degradation is not streamed by on-line systems, inspections are needed to evaluate the degradation of assets. Inspection intervals were included as a decision variable in some publications [29; $32 ; 70]$.

In addition, some researchers optimised maintenance queuing and priority rules for different assets [47; 50]. For example, if more than one machine breaks down or requires preventive maintenance at any given time, which one should be maintained first. It could be that machines in a bottleneck should have a higher priority to enhance the total throughput. It is another significant variable that received little attention. This may be due to the fact that maintenance resources were not considered in the simulation model so resource usage is not a constraint. However, it is evident that assigning different priorities to machines when maintenance resources are occupied have a direct effect on maintenance performance $[35 ; 40]$.

Spare parts management is an important component in the maintenance system and has a considerable impact on cost and availability. Several studies showed that optimizing maintenance and spare parts policies jointly led to better results compared to optimizing them separately $[72 ; 80 ; 88]$. Absence of spare parts when assets are broken extends unavailability. Whereas keeping a large inventory of spare parts results in higher costs.

Several attempts have been made to investigate the effect of production parameters on maintenance systems in manufacturing settings. The work of several authors [7; 40; 89] show that buffer size have an impact on the performance of maintenance operations. The availability of buffer between machines allows maintenance resources to be stretched on a longer time with lesser effect on production rates. On the other hand, quality initiatives such as lean, six sigma and Just In Time requires the minimisation of Wait-In-Progress.

Researchers have not treated maintenance resources in much detail. Only few included maintenance technicians [24; $25 ; 38 ; 59]$ or maintenance equipment [36] as decision variables.

\subsubsection{Constraints}

Constraints are placed on values a decision variable can take [52] or the decision variable value in relation to other variables in the system such as having the maximum stock level of a spare part should be always larger than the reorder point [61]. Alternatively, constraints can be placed at other variables such as the maximum budget that can be spent [44], 
minimum reliability level [26] or PM window where PM actions have to be taken for each machine [22]. However, it is common to not explicitly define constraints, see for example: $[45 ; 50 ; 68]$

\section{Discussion}

Simulation based optimisation has the potential to solve the increasingly complex and dynamic nature of maintenance problems and there is an increasing trend of using simulation to optimise maintenance systems. The current study found that only few real life case studies were published, the academic cases that dominate the literature such as a single machine producing a single product are oversimplified and do not reflect the complexity and interactions in real systems. Moreover, little research is directed towards optimising a system composed of several equipment and most of the research focused on optimising few equipments without considering the operation configuration.

A range of simulation based optimisation applications in maintenance systems across various industries were covered. However, few researchers examined maintenance operations in product service systems such as aircraft gas-turbine and military equipment.

Very little was found in the literature on comparing and selecting the optimum maintenance strategy. The majority of researchers investigated variations of PM including time-based PM and age-based PM. However, investigating condition based maintenance as a strategy in a production context is poorly covered in the literature.

In general, data availability does not seem to be a challenge for researchers modelling CM and PM systems. Operational data such as cycle times and arrival patterns for raw material can be obtained from the field records. Likewise, historical maintenance data such as breakdown patterns and repair times are commonly available. Cost of maintenance actions are usually simplified by using the company's standards or using calculating the hour rate based on salaries data.

However, obtaining data on the dependency between components appears to be a challenge. For example, estimating the effect of the failure of one component on the degradation of connected components. Gupta and Lawsirirat [8] suggested a dependency factor that is estimated using Failure Mode and Effect Analysis (FMEA), operational data and experts and vendors judgements. In addition, a challenge appears when attempting to model the machine degradation in CBM systems. CBM systems based on visual inspection 
can be simplified by assuming several fixed states for the asset where the transition from a state to another is based on probabilities obtained from the historical records [70]. On the other hand, CBM systems based on on-line sensors data are modelled by fitting the data into a curve and assuming it correctly reflects the change in asset's health over time [29].

Uncertainty is an inherited feature of maintenance systems. Assets' degradation depends on many factors leading to unexpected breakdowns. Human errors during inspection or maintenance can add significantly to this uncertainty. Fitting the data into statistical distributions and then sampling randomly from is a common practise used to account for this uncertainty. Special uncertainty parameters that account for human error in visual inspection can be introduced. For example, the longer the crack is on a pipe the more likely that it will be detected correctly [90]. Hennequin et al. [48] integrated fuzzy logic in the simulation to model imperfect maintenance actions according to the different skills levels of maintenance technicians.

Sensitivity analysis is used to test the robustness of optimisation results in the presence of uncertainty. It helps in evaluating the optimal solution and make the required modifications especially in areas were estimations or simplifications have been made. For example, investigating how variations in assets' thresholds levels affect the expected cost of the optimal solution [8]. Because it is difficult to obtain accurate cost data especially for conducting maintenance and inspection activities, it has been subjected to sensitivity analysis in several publications [60; 70; 91; 92]. In addition, sensitivity analysis was used to test the robustness of a suggested model by varying inputs and investigating if the results are in line with the expected outcome [42].

A vast majority of researchers used discrete event simulation to model maintenance operations. Modelling maintenance resources received little attention and the majority of researchers assumed it was readily available. On the other hand, modern optimisation methods such as GA and SA were the most reported optimisation methods in the literature. Limited research was conducted to compare the performance of multiple optimisation algorithms. One criticism of much of the literature on optimizing maintenance using classical methods is the lack of analysis of the objective function and the solution space. Therefore the justification and proper selection of the optimisation method is sometimes absent.

Minimising cost was reported as an optimisation objective in around three quarters of the literature. Moreover, limited discussion of the optimisation objectives choice was apparent in the literature. It is observed that researchers used three approaches to solve several 
objectives simultaneously: including multiple objectives in one objective function, developing a desirability function and utilising multi-objective optimisation algorithms. The latter received little attention despite its ability to solve multiple objectives simultaneously and provide the decision maker with flexibility in the maintenance dynamic environment.

Figure 6-1 presents an overview of optimal problem formulation for different types of maintenance optimisation problems. Some decision variables depend on the choice of maintenance strategy while others can be applied to all maintenance systems. In addition, if the problem includes joint optimisation of maintenance and spare parts the inventory policy parameters can be optimised. That could be either the reorder level and maximum stock level or the reorder level and order quantity. On the other hand, if the problem includes joint optimisation of maintenance and production dynamics, buffer size can be considered a decision variable. Optimisation objectives do not seem to be affected by the type of maintenance system or whether a joint optimisation is present.

\begin{tabular}{|c|c|c|c|c|c|c|c|c|c|c|}
\hline & \multicolumn{4}{|c|}{ Maintenance strategy } & \multirow{2}{*}{\multicolumn{3}{|c|}{ General maintenance }} & \multicolumn{3}{|c|}{ Joint optimisation* } \\
\hline & \multicolumn{2}{|c|}{ PM } & \multicolumn{2}{|c|}{ CBM } & & & & \multicolumn{2}{|c|}{ Spare parts } & Production \\
\hline \multirow{2}{*}{$\begin{array}{l}\text { decision } \\
\text { variables }\end{array}$} & PM & maintenance & inspection & maintenance & to & & maintenance & $\begin{array}{c}\text { reorder } \\
\text { level }\end{array}$ & $\begin{array}{c}\text { reorder } \\
\text { level }\end{array}$ & \\
\hline & frequency & schedule & frequency & threshold & & & priorities & $\begin{array}{l}\text { maximum } \\
\text { stock level }\end{array}$ & $\begin{array}{c}\text { order } \\
\text { quantity }\end{array}$ & \\
\hline objectives & \multicolumn{10}{|c|}{ min cost, max availability, max throughput } \\
\hline
\end{tabular}

Figure 6-1 Optimal problem formulation for different types of maintenance optimisation problems.

Complex maintenance problems often introduce a risk of high computation expenses. Running the simulation repeatedly during optimisation requires a considerable computation time. This can be mitigated by reducing the solution space through investigating the effect of parameters on the objective function before engaging the optimisation engine [67; 71]. Therefore leading to either eliminating some variables or reducing its ranges. High computational facilities and parallel computing can significantly reduce the computation time. Shenfield et al. [39] demonstrated the use of Grid Computing to solve a computationally intensive maintenance problem during which several clusters of computation facilities were utilised. An obvious alternative would be simplifying the problem in hand by reducing the number of variables [60].

The findings outlined in this research provide directions for future work. There seems to be a need for a detailed analysis of factors that have a significant impact on maintenance 
performance both in a production context and in product-service systems. In addition, there is a need for a framework that guides the experimenting process with different maintenance strategies and policies. The framework will assist in deciding the scope of the simulation model as well as the level of modelling detail needed. On the optimisation side, the framework can assist in the formulation of the optimisation problem.

Further research should be done to investigate condition based maintenance especially in a production context while utilising advanced tools that offer modern optimisation methods and multi-objective optimisations. There is an opportunity to research the suitability of other modern optimisation methods such as particle swarm and ant colony. There seems to be a potential for evaluating heuristics against priority rules set by various optimisation algorithms. More applications can be conducted on real life case studies.

\section{Conclusions}

Maintenance plays an important role in sustaining and improving assets availability. The aim of this research is to report the state of the art in simulation-based optimisation of maintenance operations by systematically classifying the published literature, outlining research gaps and guiding future research. Simulation based optimisation has been successfully applied to maintenance operations. Despite the limited research in this developing field, it appears to have a high potential since it allows analysing and optimizing complex maintenance systems.

Much of the research in this area is focusing on PM and optimising PM frequency that will lead to the minimum cost. Discrete event simulation was the most reported technique to model maintenance systems whereas modern optimisation methods such as GA was the most reported optimisation method in the literature.

In future investigations, it might be possible to develop a framework that guides the experimenting process with different maintenance strategies and policies. More real case studies can be conducted on multi-objective optimisation and CBM especially in a production context.

\section{Acknowledgments}

The authors would like to thank the Ministry of Higher Education in Saudi Arabia for funding this research. 


\section{References}

[1] Wang, L., Chu, J. and Mao, W. (2008), "An optimum condition-based replacement and spare provisioning policy based on Markov chains", Journal of Quality in Maintenance Engineering, vol. 14, no. 4, pp. 387-401.

[2] Wang, W. (2008), "Delay time modelling", in Kobbacy, K. and Murthy, D. N. (eds.) Complex system maintenance handbook, Springer, London, pp. 345-370.

[3] Yao, X., Fernández-Gaucherand, E., Fu, M. C. and Marcus, S. I. (2004), "Optimal preventive maintenance scheduling in semiconductor manufacturing", IEEE Transactions on Semiconductor Manufacturing, vol. 17, no. 3, pp. 345-356.

[4] Nicolai, R. P. and Dekker, R. (2008), "Optimal maintenance of multi-component systems: a review", in Kobbacy, K. and Murthy, D. N. (eds.) Complex system maintenance handbook, Springer, London, pp. 263-286.

[5] Sebastian, W. (2006), "Simulation of Manufacturing Processes", in Sauer, W. (ed.) Electronics process technology production modelling, simulation and optimisation, Springer, London, pp. 119-172.

[6] Duffuaa, S., Ben-Daya, M., Al-Sultan, K. and Andijani, A. (2001), "A generic conceptual simulation model for maintenance systems", Journal of Quality in Maintenance Engineering, vol. 7, no. 3, pp. 207-219.

[7] Rezg, N., Chelbi, A. and Xie, X. (2005), "Modeling and optimizing a joint inventory control and preventive maintenance strategy for a randomly failing production unit: Analytical and simulation approaches", International Journal of Computer Integrated Manufacturing, vol. 18, no. 2-3, pp. 225-235.

[8] Gupta, A. and Lawsirirat, C. (2006), "Strategically optimum maintenance of monitoringenabled multi-component systems using continuous-time jump deterioration models", Journal of Quality in Maintenance Engineering, vol. 12, no. 3, pp. 306-329.

[9] Marseguerra, M., Zio, E. and Podofillini, L. (2002), "Condition-based maintenance optimization by means of genetic algorithms and Monte Carlo simulation", Reliability Engineering and System Safety, vol. 77, no. 2, pp. 151-165.

[10] Briš, R. (2008), "Parallel simulation algorithm for maintenance optimization based on directed Acyclic Graph", Reliability Engineering and System Safety, vol. 93, no. 6, pp. 874-884.

[11] Allaoui, H. and Artiba, A. (2004), "Integrating simulation and optimization to schedule a hybrid flow shop with maintenance constraints", Computers and Industrial Engineering, vol. 47, no. 4, pp. 431-450.

[12] Dekker, R. (1996), "applications of maintenance optimization models: a review and analysis", Reliability Engineering and System Safety, vol. 52, no. 3, pp. 229-240. 
[13] Sharma, A., Yadava, G. and Deshmukh, S. (2011), "A literature review and future perspectives on maintenance optimization", Journal of Quality in Maintenance Engineering, vol. 17, no. 1, pp. 5-25.

[14] Garg, A. and Deshmukh, S. (2006), "Maintenance management: literature review and directions", Journal of Quality in Maintenance Engineering, vol. 12, no. 3, pp. 205-238.

[15] Amaran, S., Sahinidis, N. V., Sharda, B. and Bury, S. J. (2014), "Simulation optimization: a review of algorithms and applications", 4OR, vol. 12, no. 4, pp. 301-333.

[16] Vasili, M., Hong, T. S., Ismail, N. and Vasili, M. (2011), "Maintenance optimization models: a review and analysis", Proceedings of the 2011 International Conference on Industrial Engineering and Operations Management, 22-24 January 2011, Kuala Lumpur, Malaysia, pp. 1131-1138.

[17] Andijani, A. and Duffuaa, S. (2002), "Critical evaluation of simulation studies in maintenance systems.", Production Planning and Control, vol. 13, no. 4, pp. 336-341.

[18] Alabdulkarim, A. A., Ball, P. D. and Tiwari, A. (2013), "Applications of Simulation in Maintenance Research", World Journal of Modelling and Simulation, vol. 9, no. 1, pp. 14-37.

[19] Alrabghi, A. and Tiwari, A. (2013), "A review of simulation-based optimisation in maintenance operations", 2013 UKSim 15th International Conference on Computer Modelling and Simulation , 10-12 April 2013, Cambridge, IEEE, Piscataway, NJ, pp. 353358.

[20] Asadzadeh, S. M. and Azadeh, A. (2014), "An integrated systemic model for optimization of condition-based maintenance with human error", Reliability Engineering and System Safety, vol. 124, pp. 117-131.

[21] Rasmekomen, N. and Parlikad, A. K. (2013), "Maintenance optimization for asset systems with dependent performance degradation", IEEE Transactions on Reliability, vol. 62, no. 2, pp. 362-367.

[22] Arab, A., Ismail, N. and Lee, L. S. (2013), "Maintenance scheduling incorporating dynamics of production system and real-time information from workstations", Journal of Intelligent Manufacturing, vol. 24, no. 4, pp. 695-695.

[23] Van Horenbeek, A. and Pintelon, L. (2013), "A dynamic predictive maintenance policy for complex multi-component systems", Reliability Engineering and System Safety, vol. 120, pp. 39-50.

[24] Triki, C., Alalawin, A. and Ghiani, G. (2013), "Optimizing the performance of complex maintenance systems", 2013 5th International Conference on Modeling, Simulation and Applied Optimization, ICMSAO 2013, 28-30 April 2013, Hammamet, Tunisia, IEEE, Piscataway, NJ, pp. 1-6.

[25] Alrabghi, A., Tiwari, A. and Alabdulkarim, A. (2013), "Simulation based optimization of joint maintenance and inventory for multi-components manufacturing systems", 
Proceedings of the 2013 Winter Simulation Conference, 8-12 December 2013, Washington DC, IEEE, Piscataway, NJ, pp. 1109-1119.

[26] Schutz, J. and Rezg, N. (2013), "Maintenance strategy for leased equipment", Computers and Industrial Engineering, vol. 66, no. 3, pp. 593-600.

[27] Roux, O., Duvivier, D., Quesnel, G. and Ramat, E. (2013), "Optimization of preventive maintenance through a combined maintenance-production simulation model", International Journal of Production Economics, vol. 143, no. 1, pp. 3-12.

[28] Lynch, P., Adendorff, K., Yadavalli, V. S. S. and Adetunji, O. (2013), "Optimal spares and preventive maintenance frequencies for constrained industrial systems", Computers and Industrial Engineering, vol. 65, no. 3, pp. 378-387.

[29] Van Horenbeek, A. and Pintelon, L. (2012), "Optimal prognostic maintenance planning for multi-component systems", European Safety and Reliability Conference: Advances in Safety, Reliability and Risk Management, ESREL 2011, 18-22 September 2011, Troyes, France, pp. 910-917.

[30] Yun, W. Y., Han, Y. J. and Park, G. (2012), "Optimal preventive maintenance interval and spare parts number in a rolling stock system", 2012 International Conference on Quality, Reliability, Risk, Maintenance, and Safety Engineering, ICQR2MSE 2012, 15-18 June 2012, Chengdu, China, IEEE, Piscataway, NJ, pp. 380.

[31] Zhou, Y., Zhang, Z. and Ma, L. (2012), "Maintenance optimisation of a series-parallel system with multi-state components considering economic dependence", 2012 International Conference on Quality, Reliability, Risk, Maintenance, and Safety Engineering, ICQR2MSE 2012, 15-18 June 2012, Chengdu, China, IEEE, Piscataway, NJ, pp. 427-431.

[32] Xiang, Y., Cassady, C. R. and Pohl, E. A. (2012), "Optimal maintenance policies for systems subject to a Markovian operating environment", Computers and Industrial Engineering, vol. 62, no. 1, pp. 190-197.

[33] Gomez U., E. D., Hennequin, S. and Rezg, N. (2011), "Optimization of a failure - Prone manufacturing system with regular preventive maintenance: An IPA approach", 18th IFAC World Congress, Vol. 18, 28 August- 2 September 2011, Milan, Italy, pp. 1042210427.

[34] Um., I. S., Cheon, H. J. and Lee, H. C. (2011), "A simulation-based optimal design and analysis method for designing a train overhaul maintenance facility", Proceedings of the Institution of Mechanical Engineers, Part F: Journal of Rail and Rapid Transit, vol. 225, no. 5, pp. 523-539.

[35] Ramírez-Hernández, J. A. and Fernandez, E. (2010), "Optimization of preventive maintenance scheduling in semiconductor manufacturing models using a simulationbased approximate dynamic programming approach", Proceedings of the IEEE Conference on Decision and Control, 15-17 Dec 2010, Atlanta, GA, USA, pp. 3944-3949. 
[36] Johansson, E. C. and Jägstam, M. (2010), "Maintenance planning using simulationbased optimization", Spring Simulation Multiconference 2010, SpringSim'10, 11-15 April 2010, Orlando, Society for Computer Simulation International, San Diego, CA, pp. 1-8.

[37] Ramírez-Hernández, J. A., Crabtree, J., Yao, X., Fernandez, E., Fu, M. C., Janakiram, M., Marcus, S. I., O'Connor, M. and Patel, N. (2010), "Optimal preventive maintenance scheduling in semiconductor manufacturing systems: Software tool and simulation case studies", IEEE Transactions on Semiconductor Manufacturing, vol. 23, no. 3, pp. 477489.

[38] Tateyama, T., Tateno, T. and Shimizu, K. (2010), "Dynamic work planning by using simulation-based optimization in consideration of workers' skill and training", Journal of Advanced Mechanical Design, Systems and Manufacturing, vol. 4, no. 3, pp. 597-604.

[39] Shenfield, A., Fleming, P. J., Kadirkamanathan, V. and Allan, J. (2010), "Optimisation of maintenance scheduling strategies on the grid", Annals of Operations Research, vol. 180 , no. 1 , pp. $213-231$.

[40] Lei, Y., Liu, J., Ni, J. and Lee, J. (2010), "Production line simulation using STPN for maintenance scheduling", Journal of Intelligent Manufacturing, vol. 21, no. 2, pp. 213221.

[41] Fallah-Fini, S., Rahmandad, H., Triantis, K. and de la Garza, J. M. (2010), "Optimizing highway maintenance operations: Dynamic considerations", System Dynamics Review, vol. 26, no. 3, pp. 216-238.

[42] Boulet, J. F., Gharbi, A. and Kenn, J. P. (2009), "Multiobjective optimization in an unreliable failure-prone manufacturing system", Journal of Quality in Maintenance Engineering, vol. 15, no. 4, pp. 397-411.

[43] Boschian, V., Rezg, N. and Chelbi, A. (2009), "Contribution of simulation to the optimization of maintenance strategies for a randomly failing production system", European Journal of Operational Research, vol. 197, no. 3, pp. 1142-1149.

[44] Ng, M. W., Lin, D. Y. and Waller, S. T. (2009), "Optimal long-term infrastructure maintenance planning accounting for traffic dynamics", Computer-Aided Civil and Infrastructure Engineering, vol. 24, no. 7, pp. 459-469.

[45] Guizzi, G., Gallo, M. and Zoppoli, P. (2009), "Condition based maintenance: Simulation and optimization", Proceedings of the 8th WSEAS International Conference on System Science and Simulation in Engineering, ICOSSSE '09, 17-19 Oct 2009, Genova, Italy, pp. 319-325.

[46] Murino, T., Romano, E. and Zoppoli, P. (2009), "Maintenance policies and buffer sizing: An optimization model", WSEAS Transactions on Business and Economics, vol. 6, no. 1, pp. 21-30.

[47] Li, L. and Ni, J. (2009), "Short-term decision support system for maintenance task prioritization", International Journal of Production Economics, vol. 121, no. 1, pp. 195202. 
[48] Hennequin, S., Arango, G. and Rezg, N. (2009), "Optimization of imperfect maintenance based on fuzzy logic for a single-stage single-product production system", Journal of Quality in Maintenance Engineering, vol. 15, no. 4, pp. 412-429.

[49] Wang, S. L., Yang, N. and Schonfeld, P. (2009), "Simulation-based network maintenance planning and scheduling", Transportation Research Record, , no. 2100, pp. 94-102.

[50] Hani, Y., Amodeo, L., Yalaoui, F. and Chen, H. (2008), "Simulation based optimization of a train maintenance facility", Journal of Intelligent Manufacturing, vol. 19, no. 3, pp. 293-300.

[51] Roux, O., Jamali, M. A., Kadi, D. A. and Châtelet, E. (2008), "Development of simulation and optimization platform to analyse maintenance policies performances for manufacturing systems", International Journal of Computer Integrated Manufacturing, vol. 21 , no. 4, pp. 407-414.

[52] Oyarbide-Zubillaga, A., Goti, A. and Sanchez, A. (2008), "Preventive maintenance optimisation of multi-equipment manufacturing systems by combining discrete event simulation and multi-objective evolutionary algorithms", Production Planning and Control, vol. 19, no. 4, pp. 342-355.

[53] Dridi, L., Parizeau, M., Mailhot, A. and Villeneuve, J. P. (2008), "Using evolutionary optimization techniques for scheduling water pipe renewal considering a short planning horizon", Computer-Aided Civil and Infrastructure Engineering, vol. 23, no. 8, pp. 625635.

[54] Yang, Z., Djurdjanovic, D. and Ni, J. (2008), "Maintenance scheduling in manufacturing systems based on predicted machine degradation", Journal of Intelligent Manufacturing, vol. 19, no. 1, pp. 87-98.

[55] Ali, A., Chen, X., Yang, Z., Lee, J. and Jun, N. (2008), "Optimized maintenance design for manufacturing performance improvement using simulation", Proceedings of the 2008 Winter Simulation Conference, 7-10 Dec 2008, Miami, USA, pp. 1811-1819.

[56] Goti, A., Oyarbide-Zubillaga, A. and Sánchez, A. (2007), "Optimizing preventive maintenance by combining discrete event simulation and genetic algorithms", Hydrocarbon Processing, vol. 86, no. 10, pp. 115-116+118+120-122.

[57] Oyarbide-Zubillaga, A., Goti, A. and Sánchez, A. (2007), "Determination of the optimal maintenance frequency for a system composed by $\mathrm{N}$-machines by using discrete event simulation and genetic algorithms", Proceedings of the European Safety and Reliability Conference 2007, ESREL 2007 - Risk, Reliability and Societal Safety, Vol. 1, 25-27 June 2007, Stavanger, Norway, pp. 297-304.

[58] Ilgin, M. A. and Tunali, S. (2007), "Joint optimization of spare parts inventory and maintenance policies using genetic algorithms", International Journal of Advanced Manufacturing Technology, vol. 34, no. 5-6, pp. 594-604. 
[59] Vardar, C., Gel, E. S. and Fowler, J. W. (2007), "A framework for evaluating remote diagnostics investment decisions for semiconductor equipment suppliers", European Journal of Operational Research, vol. 180, no. 3, pp. 1411-1426.

[60] Zhou, J., Djurdjanovic, D., Ivy, J. and Ni, J. (2007), "Integrated reconfiguration and agebased preventive maintenance decision making", IIE Transactions (Institute of Industrial Engineers), vol. 39, no. 12, pp. 1085-1102.

[61] Chen, M. C., Hsu, C. M. and Chen, S. W. (2006), "Optimizing joint maintenance and stock provisioning policy for a multi-echelon spare part logistics network", Journal of the Chinese Institute of Industrial Engineers, vol. 23, no. 4, pp. 289-302.

[62] Chootinan, P., Chen, A., Horrocks, M. R. and Bolling, D. (2006), "A multi-year pavement maintenance program using a stochastic simulation-based genetic algorithm approach", Transportation Research Part A: Policy and Practice, vol. 40, no. 9, pp. 725743.

[63] El Hayek, M., Van Voorthuysen, E. and Kelly, D. W. (2005), "Optimizing life cycle cost of complex machinery with rotable modules using simulation", Journal of Quality in Maintenance Engineering, vol. 11, no. 4, pp. 333-347.

[64] Gharbi, A. and Kenné, J. P. (2005), "Maintenance scheduling and production control of multiple-machine manufacturing systems", Computers and Industrial Engineering, vol. 48, no. 4, pp. 693-707.

[65] Shalaby, M. A., Gomaa, A. M. and Mohib, A. M. (2004), "A genetic algorithm for preventive maintenance scheduling in a multi-unit multi-state system", Journal of Engineering and Applied Science, vol. 51, no. 4, pp. 795-811.

[66] Kenné, J. P. and Gharbi, A. (2004), "Stochastic optimal production control problem with corrective maintenance", Computers and Industrial Engineering, vol. 46, no. 4 special issue, pp. 865-875.

[67] Rezg, N., Xie, X. and Mati, Y. (2004), "Joint optimization of preventive maintenance and inventory control in a production line using simulation", International Journal of Production Research, vol. 42, no. 10, pp. 2029-2046.

[68] Cheu, R. L., Wang, Y. and Fwa, T. F. (2004), "Genetic algorithm-simulation methodology for pavement maintenance scheduling", Computer-Aided Civil and Infrastructure Engineering, vol. 19, no. 6, pp. 446-455.

[69] Marquez, A. C., Gupta, J. N. D. and Heguedas, A. S. (2003), "Maintenance policies for a production system with constrained production rate and buffer capacity", International Journal of Production Research, vol. 41, no. 9, pp. 1909-1926.

[70] Kuntz, P. A., Christie, R. D. and Venkata, S. S. (2001), "A reliability centered optimal visual inspection model for distribution feeders", IEEE Transactions on Power Delivery, vol. 16, no. 4, pp. 718-723. 
[71] Cavory, G., Dupas, R. and Goncalves, G. (2001), "A genetic approach to the scheduling of preventive maintenance tasks on a single product manufacturing production line", International Journal of Production Economics, vol. 74, no. 1-3, pp. 135-146.

[72] Sarker, R. and Haque, A. (2000), "Optimization of maintenance and spare provisioning policy using simulation", Applied Mathematical Modelling, vol. 24, no. 10, pp. 751-760.

[73] Richard Cassady, C., Bowden, R. O., Liew, L. and Pohl, E. A. (2000), "Combining preventive maintenance and statistical process control: a preliminary investigation", IIE Transactions (Institute of Industrial Engineers), vol. 32, no. 6, pp. 471-478.

[74] Petrović, R., Šenborn, A. and Vujošević, M. (1982), "Spares allocation in the presence of uncertainty", European Journal of Operational Research, vol. 11, no. 1, pp. 77-81.

[75] Van Horenbeek, A., Buré, J., Cattrysse, D., Pintelon, L. and Vansteenwegen, P. (2013), "Joint maintenance and inventory optimization systems: a review", International Journal of Production Economics, vol. 143, no. 2, pp. 499-508.

[76] Manzini, R., Regattieri, A., Pham, H. and Ferrari, E. (2010), Maintenance for Industrial Systems, Springer, London.

[77] Wang, W. (2008), "Condition-based maintenance modelling", in Kobbacy, K. and Murthy, D. N. (eds.) Complex System Maintenance Handbook, Springer, London, pp. 111-131.

[78] Robinson, S. (2007), Simulation : the practice of model development and use, Wiley, Chichester.

[79] Verma, A., Srividya, A. and Gaonkar, R. (2007), "Maintenance and replacement interval optimization using possibilistic approach", International Journal of Modelling and Simulation, vol. 27, no. 2, pp. 193-199.

[80] Bruzzone, A. and Bocca, E. (2012), "Innovative solutions based on simulation combined with optimization techniques for maintenance service management within complex systems", International Journal of Modeling, Simulation, and Scientific Computing, vol. 3, no. 2, pp. 1-23.

[81] Jahangirian, M., Eldabi, T., Naseer, A., Stergioulas, L. K. and Young, T. (2010), "Simulation in manufacturing and business: A review", European Journal of Operational Research, vol. 203, no. 1, pp. 1-13.

[82] Banks, J. (2010), Discrete-event system simulation, Pearson, Upper Saddle River.

[83] Rao, S. S. (2009), Engineering optimization theory and practice, John Wiley \& Sons, Hoboken, N.J.

[84] Deb, K. (2005), Optimization for engineering design: algorithms and examples, Prentice-Hall, New Delhi. 
[85] Biethahn, J. and Nissen, V. (1994), "Combinations of simulation and evolutionary algorithms in management science and economics", Annals of Operations Research, vol. 52, no. 4, pp. 181-208.

[86] Bäck, T. and Schwefel, H. (1993), "An overview of evolutionary algorithms for parameter optimization", Evolutionary computation, vol. 1, no. 1, pp. 1-23.

[87] Belegundu, A. D. and Chandrupatla, T. R. (2011), Optimization concepts and applications in engineering, Cambridge University Press, New York.

[88] Zohrul Kabir, A. and Farrash, S. (1996), "Simulation of an integrated age replacement and spare provisioning policy using SLAM", Reliability Engineering \& System Safety, vol. 52, no. 2, pp. 129-138.

[89] Azadivar, F. and Shu, J. V. (1998), "Use of simulation in optimization of maintenance policies", Proceedings of the 1998 Winter Simulation Conference, Vol. 2, 13-16 December 1998, Washington, pp. 1061-1067.

[90] Beaurepaire, P., Valdebenito, M. A., Schuëller, G. I. and Jensen, H. A. (2012), "Reliability-based optimization of maintenance scheduling of mechanical components under fatigue", Computer Methods in Applied Mechanics and Engineering, vol. 221222, no. 0, pp. 24-40.

[91] Gomes, W. J. S., Beck, A. T. and Haukaas, T. (2013), "Optimal inspection planning for onshore pipelines subject to external corrosion", Reliability Engineering \& System Safety, vol. 118, no. 0, pp. 18-27.

[92] Valdebenito, M. A. and Schuëller, G. I. (2010), "Design of maintenance schedules for fatigue-prone metallic components using reliability-based optimization", Computer Methods in Applied Mechanics and Engineering, vol. 199, no. 33-36, pp. 2305-2318.

[93] Xie, J. and Wang, H. (2008), "Joint optimization of condition-based preventive maintenance and spare ordering policy", 2008 International Conference on Wireless Communications, Networking and Mobile Computing, WiCOM 2008, 12 October 2008 through 14 October 2008, Dalian, China, pp. 1-5. 


\section{Appendix A}

\begin{tabular}{|c|c|c|c|c|c|c|c|c|c|c|c|c|c|c|c|c|c|}
\hline \multirow[b]{2}{*}{ 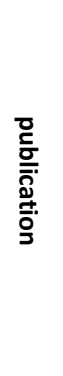 } & \multirow[b]{2}{*}{ 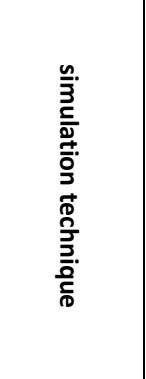 } & \multirow[b]{2}{*}{ 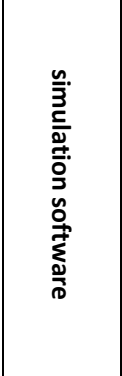 } & \multirow[b]{2}{*}{ 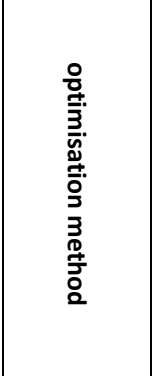 } & \multirow[b]{2}{*}{ 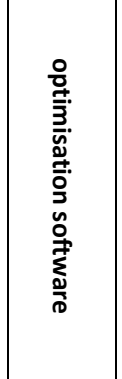 } & \multirow[b]{2}{*}{ 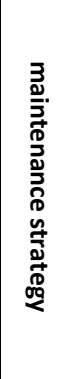 } & \multirow[b]{2}{*}{ 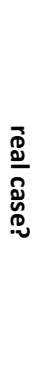 } & \multicolumn{9}{|c|}{ Decision variables } & \multirow[b]{2}{*}{ 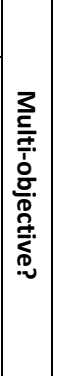 } & \multirow[b]{2}{*}{ 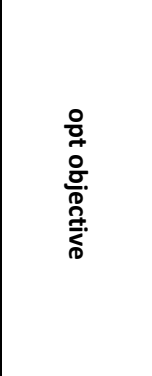 } \\
\hline & & & & & & & $\begin{array}{l}0 \\
0 \\
3 \\
\overrightarrow{7} \\
0 \\
\frac{0}{2} \\
\frac{1}{1} \\
2 \\
2\end{array}$ & 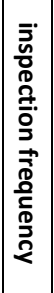 & 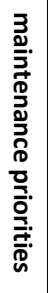 & 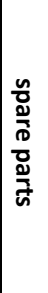 & 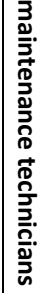 & 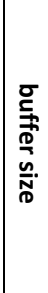 & 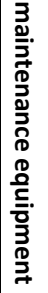 & 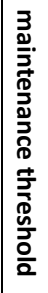 & 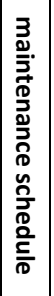 & & \\
\hline [20] & DES & matlab & $\begin{array}{l}\text { Fibonacci } \\
\text { algorithm }\end{array}$ & $\begin{array}{c}\text { not } \\
\text { disclosed }\end{array}$ & $\mathrm{CBM}$ & no & no & no & no & no & no & no & no & yes & no & no & $\min$ cost \\
\hline [27] & DES & $\begin{array}{c}\text { VLE } \\
\text { simulator }\end{array}$ & $\begin{array}{c}\text { direct search } \\
\text { Nelder- } \\
\text { Mead } \\
\text { (simplex) } \\
\text { method } \\
\end{array}$ & $\begin{array}{c}\text { not } \\
\text { disclosed }\end{array}$ & PM & no & yes & no & no & no & no & no & no & no & no & no & $\begin{array}{c}\max \\
\text { availability }\end{array}$ \\
\hline [22] & DES & Promodel & GA & $\begin{array}{c}\text { SimRunn } \\
\text { er }\end{array}$ & PM & yes & yes & no & no & no & no & no & no & no & no & no & $\begin{array}{c}\text { max total } \\
\text { throughout }\end{array}$ \\
\hline [28] & agent based & Anylogic & ga & \begin{tabular}{|c|} 
OptQues \\
$\mathrm{t}$
\end{tabular} & PM & yes & yes & no & no & yes & no & no & no & no & no & no & $\min$ cost \\
\hline [24] & agent based & Java & $\begin{array}{c}\text { Approximat } \\
\text { ed } \\
\text { Neighbourh } \\
\text { ood } \\
\text { Evaluation } \\
\text { (local } \\
\text { search) }\end{array}$ & $\begin{array}{c}\text { IBM } \\
\text { ILOG } \\
\text { CPLEX } \\
12.3\end{array}$ & $\mathrm{CM}$ & no & no & no & no & yes & yes & no & no & no & no & no $r$ & $\begin{array}{l}\text { min life cycle } \\
\text { maintenance } \\
\text { cost }\end{array}$ \\
\hline [25] & DES & witness & $\begin{array}{c}\text { simulated } \\
\text { annealing + } \\
\text { random } \\
\text { solution + } \\
\text { climb hill } \\
\end{array}$ & \begin{tabular}{|c} 
witness \\
optimize \\
$r$ \\
\end{tabular} & PM & no & yes & no & no & yes & yes & no & no & no & no & no & $\begin{array}{c}\text { min total } \\
\text { cost }\end{array}$ \\
\hline [26] & DES & $\begin{array}{c}\text { not } \\
\text { disclosed }\end{array}$ & manual & $\begin{array}{c}\text { not } \\
\text { disclosed }\end{array}$ & PM & no & yes & no & no & no & no & no & no & no & no & no & $\min$ cost \\
\hline [23] & DES & $\begin{array}{c}\text { not } \\
\text { disclosed }\end{array}$ & $\begin{array}{l}\text { Penalty } \\
\text { function }\end{array}$ & \begin{tabular}{|c|} 
not \\
disclosed
\end{tabular} & CBM & no & Yes & no & no & no & no & no & no & no & yes & no & $\min$ cost \\
\hline [21] & $\begin{array}{c}\text { not } \\
\text { disclosed }\end{array}$ & $\begin{array}{c}\text { not } \\
\text { disclosed }\end{array}$ & manual & \begin{tabular}{c|} 
not \\
disclosed
\end{tabular} & PM & no & yes & no & no & no & no & no & no & no & no & no & max profit \\
\hline [29] & DES & $\begin{array}{c}\text { not } \\
\text { disclosed }\end{array}$ & GA & $\begin{array}{c}\text { not } \\
\text { disclosed }\end{array}$ & CBM & yes & yes & yes & no & no & no & no & no & yes & no & yes & $\begin{array}{c}\text { cost and } \\
\text { availability }\end{array}$ \\
\hline [31] & $\begin{array}{c}\text { not } \\
\text { disclosed }\end{array}$ & $\begin{array}{c}\text { not } \\
\text { disclosed }\end{array}$ & $\begin{array}{c}\text { not } \\
\text { disclosed }\end{array}$ & $\begin{array}{c}\text { not } \\
\text { disclosed }\end{array}$ & CBM & no & no & no & no & no & no & no & no & yes & no & no & $\begin{array}{l}\text { max avg } \\
\text { revenue per } \\
\text { unit time }\end{array}$ \\
\hline [32] & \begin{tabular}{|c|} 
DES for \\
systems \\
states and \\
continuous \\
for machine \\
degradation
\end{tabular} & $\begin{array}{c}\text { not } \\
\text { disclosed }\end{array}$ & $\begin{array}{c}\text { direct search } \\
\text { cyclic } \\
\text { coordinate } \\
\text { method }\end{array}$ & $\begin{array}{c}\text { not } \\
\text { enough } \\
\text { info }\end{array}$ & CBM & no & yes & yes & no & no & no & no & no & yes & no & no & $\min$ cost \\
\hline [30] & $\begin{array}{c}\text { not } \\
\text { disclosed }\end{array}$ & $\begin{array}{c}\text { not } \\
\text { disclosed }\end{array}$ & $\begin{array}{c}\mathrm{GA}+ \\
\text { simulated } \\
\text { annealing }\end{array}$ & $\begin{array}{c}\text { not } \\
\text { disclosed }\end{array}$ & PM & yes & yes & no & no & yes & no & no & no & no & no & no & $\min$ cost \\
\hline [33] & DES & $\begin{array}{c}\text { not } \\
\text { disclosed }\end{array}$ & \begin{tabular}{|c|} 
IPA \\
infinitesimal \\
perturbation \\
analysis \\
\end{tabular} & $\begin{array}{c}\text { not } \\
\text { disclosed }\end{array}$ & PM & no & yes & no & no & no & no & yes & no & no & no & no & $\min$ cost \\
\hline [37] & DES & $\begin{array}{c}\text { PMOST, } \\
\text { AutoSche } \\
\text { d AP }\end{array}$ & $\begin{array}{c}\text { not } \\
\text { disclosed }\end{array}$ & \begin{tabular}{|c} 
IBM \\
optimisa \\
tion \\
software \\
library \\
and ILOG \\
CPLEX
\end{tabular} & PM & yes & yes & no & no & no & no & no & no & no & no & yes & $\begin{array}{l}\quad \max \\
\text { availability. } \\
\text { min PM and } \\
\text { inventory } \\
\text { costs, max } \\
\text { throughput }\end{array}$ \\
\hline
\end{tabular}




\begin{tabular}{|c|c|c|c|c|c|c|c|c|c|c|c|c|c|c|c|c|c|}
\hline [39] & DES & MEAROS & GA & $\begin{array}{c}\text { not } \\
\text { disclosed }\end{array}$ & PM & no & no & no & no & no & no & no & no & yes & no & no & $\min$ cost \\
\hline [40] & $\begin{array}{l}\text { Stochastic } \\
\text { Petri-Nets }\end{array}$ & $\begin{array}{c}\text { not } \\
\text { disclosed }\end{array}$ & $\begin{array}{c}\text { manually by } \\
\text { running } \\
\text { simulation } \\
\text { scenarios }\end{array}$ & $\begin{array}{c}\text { not } \\
\text { disclosed }\end{array}$ & PM & no & yes & no & yes & no & no & yes & no & no & no & no & $\begin{array}{c}\min \\
\text { maintenance } \\
\text { cost and max } \\
\text { through } \\
\text { output }\end{array}$ \\
\hline [36] & $\begin{array}{c}\text { not } \\
\text { disclosed }\end{array}$ & $\begin{array}{c}\text { not } \\
\text { disclosed }\end{array}$ & GA NSGA 2 & Python & CBM & no & no & no & no & no & no & no & yes & no & no & yes & \begin{tabular}{|c|} 
min shop \\
capacity, min \\
cost and max \\
availability \\
\end{tabular} \\
\hline [34] & DES & automod & $\begin{array}{c}\text { evolution } \\
\text { strategy }\end{array}$ & autoStat & CBM & yes & no & no & no & no & no & no & no & no & no & no & \begin{tabular}{|c|}
$\max$ \\
throughput \\
\end{tabular} \\
\hline [35] & \begin{tabular}{|c|} 
approximate \\
dynamic \\
programmin \\
g
\end{tabular} & automod & $\begin{array}{l}\text { markov } \\
\text { decision } \\
\text { process }\end{array}$ & automod & PM & no & no & no & yes & no & no & no & no & no & no & no & $\begin{array}{c}\text { minimise } \\
\text { WIP and CT }\end{array}$ \\
\hline [38] & agent based & $\begin{array}{c}\text { not } \\
\text { disclosed }\end{array}$ & GA & $\begin{array}{c}\text { not } \\
\text { disclosed }\end{array}$ & PM & no & no & no & no & no & yes & no & no & no & no & yes & \begin{tabular}{|} 
min working \\
hours and \\
max no of \\
skilled \\
workers \\
\end{tabular} \\
\hline [41] & Continuous & VENSIM & $\begin{array}{c}\text { not } \\
\text { disclosed }\end{array}$ & VENSIM & PM & yes & no & no & yes & no & no & no & no & yes & no & no & $\begin{array}{c}\text { min distress } \\
\text { on roads }\end{array}$ \\
\hline [44] & \begin{tabular}{|c} 
DES : cell \\
transmission \\
model - \\
mesoscopic \\
traffic \\
simulation
\end{tabular} & $\mathrm{C}++$ & GA & $\mathrm{C}++$ & PM & no & yes & no & no & no & no & no & no & no & no & no & $\begin{array}{c}\text { min cost and } \\
\text { travel time } \\
\text { for users }\end{array}$ \\
\hline [48] & DES & matlab & $\begin{array}{c}\text { manual } \\
\text { optimisation }\end{array}$ & matlab & PM & no & yes & no & no & no & no & no & no & no & no & no & \begin{tabular}{|c|}
$\max$ \\
availability or \\
min cost
\end{tabular} \\
\hline [45] & DES & Arena & \begin{tabular}{|c|} 
different \\
optimisation \\
algorithms \\
(OptQuest)
\end{tabular} & $\begin{array}{c}\text { OptQues } \\
\mathrm{t}\end{array}$ & CBM & no & no & no & no & no & no & no & no & yes & no & no & $\min$ cost \\
\hline [46] & DES & arena & \begin{tabular}{|c|} 
different \\
optimisation \\
algorithm \\
included in \\
OptQuest \\
\end{tabular} & $\begin{array}{c}\text { OptQues } \\
\mathrm{t}\end{array}$ & CBM & no & no & no & no & no & no & yes & no & no & no & no & $\min$ cost \\
\hline [42] & DES & $\begin{array}{c}\text { visual } \\
\text { slam } \\
\text { language }\end{array}$ & \begin{tabular}{|c|} 
manual and \\
anova using \\
multi- \\
criteria \\
decision \\
making \\
\end{tabular} & $\begin{array}{c}\text { statgrap } \\
\text { hics }\end{array}$ & PM & no & yes & no & no & yes & no & no & no & no & no & no & $\begin{array}{c}\min \text { cost and } \\
\max \\
\text { availability }\end{array}$ \\
\hline [47] & DES & excel & $\begin{array}{c}\text { manual } \\
\text { optimisation }\end{array}$ & $\begin{array}{c}\text { not } \\
\text { disclosed }\end{array}$ & PM & yes & no & no & yes & no & no & no & no & no & no & no & \begin{tabular}{|c|}
$\min$ \\
maintenance \\
cost
\end{tabular} \\
\hline [43] & DES & $\begin{array}{c}\text { java } \\
\text { language }\end{array}$ & \begin{tabular}{|c|} 
manually by \\
running \\
simulation \\
scenarios
\end{tabular} & $\begin{array}{c}\text { manually } \\
\text { by } \\
\text { running } \\
\text { simulatio } \\
n \\
\text { scenarios } \\
+ \\
\text { NEMROD }\end{array}$ & PM & no & yes & no & no & no & no & no & no & no & no & no & $\begin{array}{c}\text { min sys cost } \\
\text { or max } \\
\text { availability }\end{array}$ \\
\hline [49] & DES & $\begin{array}{c}\text { not } \\
\text { disclosed }\end{array}$ & GA & $\begin{array}{c}\text { not } \\
\text { disclosed }\end{array}$ & PM & yes & yes & no & no & no & no & no & no & no & no & no & $\begin{array}{l}\text { max net } \\
\text { present } \\
\text { worth }\end{array}$ \\
\hline [50] & DES & Arena & $\begin{array}{c}\text { GA with } \\
\text { multi- } \\
\text { objective } \\
\text { function: } \\
\text { pareto } \\
\text { (NSGA2) and } \\
\text { non-pareto }\end{array}$ & $\begin{array}{l}\text { visual } \\
\text { basic }\end{array}$ & PM & yes & no & no & yes & no & no & no & no & no & no & yes & $\begin{array}{c}\text { max } \\
\text { production } \\
\text { rate- min } \\
\text { total } \\
\text { immobilizatio } \\
\mathrm{n} \text { time- min } \\
\text { occupation } \\
\text { rates }\end{array}$ \\
\hline
\end{tabular}




\begin{tabular}{|c|c|c|c|c|c|c|c|c|c|c|c|c|c|c|c|c|c|}
\hline [54] & DES & $\begin{array}{c}\text { not } \\
\text { disclosed } \\
\end{array}$ & GA & $\begin{array}{c}\text { not } \\
\text { disclosed } \\
\end{array}$ & CBM & no & no & no & no & no & no & no & no & no & yes & no & max profit \\
\hline [53] & $\begin{array}{c}\text { not } \\
\text { disclosed }\end{array}$ & Epanet2.0 & $\begin{array}{c}\text { GA, NPGA-2, } \\
\text { NSGA-II }\end{array}$ & $\mathrm{C}++$ & PM & no & yes & no & no & no & no & no & no & no & no & no & $\min$ cost \\
\hline [93] & DES & $\begin{array}{c}\text { not } \\
\text { disclosed }\end{array}$ & GA & $\begin{array}{c}\text { not } \\
\text { disclosed }\end{array}$ & CBM & no & no & yes & no & yes & no & no & no & no & no & no & $\min$ cost \\
\hline [51] & DES & \begin{tabular}{|c|} 
resource - \\
action - \\
operation
\end{tabular} & $\begin{array}{c}\text { direct search } \\
\text { Nelder- } \\
\text { Mead }\end{array}$ & $\begin{array}{c}\text { not } \\
\text { disclosed }\end{array}$ & PM & no & yes & no & no & no & no & no & no & no & no & no & $\min$ cost \\
\hline [55] & DES & Arena & \begin{tabular}{|c|} 
different \\
optimisation \\
algorithm \\
included in \\
ISSOP \\
software \\
such as \\
enumeratio \\
n, quasi \\
gradient \\
strategy, \\
Monte Carlo \\
strategy and \\
GA
\end{tabular} & \begin{tabular}{|c|} 
\\
ISSOP \\
(intellige \\
nt \\
system \\
for \\
simulatio \\
n and \\
optimisa \\
tion) \\
\end{tabular} & $\mathrm{CM}$ & yes & no & no & no & no & no & no & no & no & no & yes & $\begin{array}{l}\text { min costs, } \\
\text { max orders } \\
\text { and min } \\
\text { process time }\end{array}$ \\
\hline [52] & DES & $\begin{array}{c}\text { witness + } \\
\text { Monte } \\
\text { Carlo }\end{array}$ & $\begin{array}{c}\text { GA NSGA } 2 \text { - } \\
\text { multi- } \\
\text { objective } \\
\text { evolutionary } \\
\text { algorithms }\end{array}$ & matlab & PM & yes & yes & no & no & no & no & no & no & no & no & yes & $\begin{array}{l}\text { minimise } \\
\text { cost and } \\
\text { maximise } \\
\text { profit }\end{array}$ \\
\hline [57] & DES & Witness & GA NSG2 & Matlab & PM & yes & yes & no & no & no & no & no & no & no & no & yes & $\begin{array}{c}\min \text { cost and } \\
\text { max profit }\end{array}$ \\
\hline [58] & DES & Arena & GA & $\begin{array}{c}\text { not } \\
\text { disclosed }\end{array}$ & PM & yes & yes & no & no & yes & no & no & no & no & no & no & $\min$ cost \\
\hline [60] & DES & Promodel & GA & $\begin{array}{c}\text { SimRunn } \\
\text { er }\end{array}$ & PM & no & yes & no & no & no & no & no & no & yes & no & no & $\min$ cost \\
\hline [56] & DES & $\begin{array}{c}\text { not } \\
\text { disclosed }\end{array}$ & \begin{tabular}{|c|} 
GA multi- \\
objective \\
evolutionary \\
algorithms \\
NSGA-II
\end{tabular} & \begin{tabular}{|} 
not \\
enough \\
info
\end{tabular} & PM & yes & yes & no & no & no & no & no & no & no & no & yes & $\begin{array}{l}\text { min cost and } \\
\text { max profit }\end{array}$ \\
\hline [59] & $\begin{array}{c}\text { not } \\
\text { disclosed }\end{array}$ & $\mathrm{C}++$ & GA & $\mathrm{C}++$ & $\mathrm{CM}$ & no & no & no & no & no & yes & no & no & no & no & no & $\min$ cost \\
\hline [61] & DES & Arena & $\begin{array}{l}\text { scatter } \\
\text { search }\end{array}$ & $\begin{array}{c}\text { OptQues } \\
t\end{array}$ & PM & no & no & no & no & yes & no & no & no & no & no & no & max profit \\
\hline [8] & $\begin{array}{c}\text { continuous - } \\
\text { Euler } \\
\text { scheme }\end{array}$ & $\begin{array}{c}\text { not } \\
\text { disclosed }\end{array}$ & \begin{tabular}{|c|} 
direct \\
search: \\
simple \\
search in the \\
space of \\
decision \\
variables \\
\end{tabular} & not & CBM & no & no & no & no & no & no & no & no & no & no & no & $\min$ cost \\
\hline [62] & $\begin{array}{c}\text { Latin } \\
\text { hypercube } \\
\text { sampling }\end{array}$ & $\begin{array}{c}\text { not } \\
\text { disclosed }\end{array}$ & GA & $\begin{array}{c}\text { not } \\
\text { disclosed }\end{array}$ & PM & no & no & no & no & no & no & no & no & no & no & no & $\begin{array}{c}\text { min cost or } \\
\text { max } \\
\text { performance }\end{array}$ \\
\hline [63] & DES & ARENA & $\begin{array}{c}\text { manual } \\
\text { optimisation }\end{array}$ & \begin{tabular}{|c|} 
not \\
disclosed
\end{tabular} & PM & yes & yes & no & no & no & no & no & no & no & no & no & $\begin{array}{c}\text { max } \\
\text { availability }\end{array}$ \\
\hline [7] & DES & Promodel & $\begin{array}{c}\text { manual and } \\
\text { design of } \\
\text { experiments }\end{array}$ & $\begin{array}{c}\text { statgrap } \\
\text { hics }\end{array}$ & PM & no & yes & no & no & no & no & yes & no & no & no & no & $\min$ cost \\
\hline [64] & \begin{tabular}{|c} 
DES in \\
general but \\
continuous \\
for machine \\
aging and \\
inventory of \\
products
\end{tabular} & $\begin{array}{c}\text { visual } \\
\text { slam } \\
\text { language }\end{array}$ & $\begin{array}{c}\text { manual and } \\
\text { design of } \\
\text { experiments }\end{array}$ & $\begin{array}{c}\text { statgrap } \\
\text { hics }\end{array}$ & PM & no & yes & no & no & no & no & no & no & no & no & no & $\min$ cost \\
\hline
\end{tabular}




\begin{tabular}{|c|c|c|c|c|c|c|c|c|c|c|c|c|c|c|c|c|c|}
\hline [3] & $\begin{array}{c}\text { mixed- } \\
\text { integer } \\
\text { programmin } \\
\mathrm{g}\end{array}$ & $\begin{array}{c}\text { IBM } \\
\text { EasyMod } \\
\text { eler }\end{array}$ & $\begin{array}{c}\text { not } \\
\text { disclosed }\end{array}$ & $\begin{array}{c}\text { OSL } \\
\text { package }\end{array}$ & PM & yes & yes & no & no & no & no & no & no & no & no & no & $\begin{array}{c}\text { max } \\
\text { availability. } \\
\text { Min } \\
\text { inventory, } \\
\text { min PM } \\
\text { costs, max } \\
\text { throughput }\end{array}$ \\
\hline [11] & DES & $\begin{array}{c}\text { resource - } \\
\text { action - } \\
\text { operation }\end{array}$ & $\begin{array}{l}\text { simulated } \\
\text { annealing }\end{array}$ & $\begin{array}{l}\text { psudo } \\
\text { code }\end{array}$ & $\mathrm{CM}$ & no & no & no & no & no & no & no & no & no & no & no & \begin{tabular}{|c} 
min \\
completion \\
time (of all \\
prescribed \\
jobs), \\
conformance \\
to promised \\
jobs delivery \\
dates?, min \\
WIP
\end{tabular} \\
\hline [65] & $\begin{array}{c}\text { not } \\
\text { disclosed }\end{array}$ & MATLAB & GA & $\begin{array}{c}\text { not } \\
\text { disclosed }\end{array}$ & PM & yes & yes & no & no & no & no & no & no & no & no & no & min cost \\
\hline [66] & $\begin{array}{l}\text { markov } \\
\text { chains }\end{array}$ & $\begin{array}{c}\text { not } \\
\text { disclosed }\end{array}$ & $\begin{array}{c}\text { manual and } \\
\text { design of } \\
\text { experiments }\end{array}$ & $\begin{array}{c}\text { statgrap } \\
\text { hics }\end{array}$ & $\mathrm{CM}$ & no & no & no & no & no & no & no & no & no & no & no & $\min$ cost \\
\hline [67] & DES & Promodel & GA & \begin{tabular}{|c|} 
not \\
disclosed
\end{tabular} & PM & no & yes & no & no & no & no & no & no & no & no & no & $\min$ cost \\
\hline [68] & $\begin{array}{c}\text { traffic } \\
\text { simulator }\end{array}$ & paramics & GA & $\begin{array}{c}\text { not } \\
\text { disclosed }\end{array}$ & PM & no & no & no & no & no & no & no & no & no & yes & no & $\begin{array}{c}\text { min total } \\
\text { travel time } \\
\text { for vehicles }\end{array}$ \\
\hline [69] & $\begin{array}{c}\text { system } \\
\text { dynamics }\end{array}$ & $\begin{array}{c}\text { not } \\
\text { disclosed }\end{array}$ & $\begin{array}{c}\text { the modified } \\
\text { powell } \\
\text { method }\end{array}$ & $\begin{array}{l}\text { direct } \\
\text { search }\end{array}$ & PM & no & yes & no & no & no & no & yes & no & no & no & no & $\begin{array}{c}\text { min cost and } \\
\text { max } \\
\text { availability } \\
\end{array}$ \\
\hline [71] & DES & $\mathrm{C}++\mathrm{SIM}$ & GA & $\begin{array}{c}\text { not } \\
\text { disclosed }\end{array}$ & PM & yes & yes & no & no & no & no & no & no & no & no & no & $\begin{array}{c}\text { max } \\
\text { throughput }\end{array}$ \\
\hline [70] & $\begin{array}{l}\text { markov } \\
\text { chains }\end{array}$ & $\begin{array}{c}\text { not } \\
\text { disclosed }\end{array}$ & \begin{tabular}{|c|} 
manually by \\
running \\
simulation \\
scenarios \\
\end{tabular} & $\begin{array}{c}\text { not } \\
\text { disclosed }\end{array}$ & CBM & yes & no & yes & no & no & no & no & no & no & no & no & $\begin{array}{l}\text { min cost of } \\
\text { inspection, } \\
\text { repair and } \\
\text { reliability }\end{array}$ \\
\hline [73] & DES & $\begin{array}{c}\text { not } \\
\text { disclosed } \\
\end{array}$ & $\mathrm{EA}$ & \begin{tabular}{|c|} 
not \\
disclosed
\end{tabular} & PM & no & yes & no & no & no & no & no & no & no & no & no & $\min$ cost \\
\hline [72] & DES & \begin{tabular}{|c|} 
SIMSCRIP \\
T II.5 \\
\end{tabular} & $\begin{array}{c}\text { not } \\
\text { disclosed }\end{array}$ & $\begin{array}{c}\text { not } \\
\text { disclosed }\end{array}$ & PM & no & yes & no & no & yes & no & no & no & no & no & no & $\min$ cost \\
\hline [74] & $\begin{array}{c}\text { not } \\
\text { disclosed }\end{array}$ & simne & $\begin{array}{c}\text { not } \\
\text { disclosed }\end{array}$ & $\begin{array}{c}\text { not } \\
\text { disclosed }\end{array}$ & $\mathrm{CM}$ & no & no & no & no & yes & no & no & no & no & no & no & not disclosed \\
\hline
\end{tabular}


2014-12-29

State of the art in simulation-based optimisation for maintenance systems

\author{
Alrabghi, Abdullah
}

Elsevier

Abdullah Alrabghi and Ashutosh Tiwari. State of the art in simulation-based optimisation for maintenance systems. Computers and Industrial Engineering, Volume 82, April 2015, Pages 167-182 https://doi.org/10.1016/j.cie.2014.12.022

Downloaded from Cranfield Library Services E-Repository 